\title{
Dialectic tensions in the financial markets: a longitudinal study of pre- and post-crisis regulatory technology
}

Article

Accepted Version

Currie, W. L., Gozman, D. P. and Seddon, J. J. M. (2018) Dialectic tensions in the financial markets: a longitudinal study of pre- and post-crisis regulatory technology. Journal of Information Technology, 33 (4). pp. 304-325. ISSN 0268-3962 doi: https://doi.org/10.1057/s41265-017-0047-5 Available at https://centaur.reading.ac.uk/73644/

It is advisable to refer to the publisher's version if you intend to cite from the work. See Guidance on citing.

To link to this article DOI: http://dx.doi.org/10.1057/s41265-017-0047-5

Publisher: Palgrave Macmillan

All outputs in CentAUR are protected by Intellectual Property Rights law, including copyright law. Copyright and IPR is retained by the creators or other copyright holders. Terms and conditions for use of this material are defined in the End User Agreement.

www.reading.ac.uk/centaur 
Central Archive at the University of Reading

Reading's research outputs online 


\title{
Dialectic Tensions in the Financial Markets: A Longitudinal Study of Pre and Post Crisis Regulatory Technology
}

\begin{abstract}
This article presents the findings from a longitudinal research study on regulatory technology in the UK financial services industry. The financial crisis with serious corporate and mutual fund scandals raised the profile of compliance as governmental bodies, institutional and private investors introduced a 'tsunami' of financial regulations. Adopting a multi-level analysis, this study examines how regulatory technology was used by financial firms to meet their compliance obligations, pre and post-crisis. Empirical data collected over twelve years examines the deployment of an investment management system in eight financial firms. Interviews with public regulatory bodies, financial institutions and technology providers reveal a culture of compliance with increased transparency, surveillance, and accountability. Findings show that dialectic tensions arise as the pursuit of transparency, surveillance and accountability in compliance mandates is simultaneously rationalized, facilitated and obscured by regulatory technology. Responding to these challenges, regulatory bodies continue to impose revised compliance mandates on financial firms to force them to adapt their financial technologies in an ever-changing multi-jurisdictional regulatory landscape.
\end{abstract}

Keywords: Regulatory Technology, Compliance Systems, Financial Technology, Financial Crisis, Surveillance, Ethics, Accountability, Fintech, Regtech, 


\section{Introduction}

The financial scandals of the previous decade have unleashed a 'tsunami' of regulations to force the financial markets to improve external reporting, internal controls and ultimately transparency. Such developments are often rationalised by regulatory bodies as introduced to benefit a variety of stakeholders from the wider society to the individual investor (Mikes 2009; Power, 2000). High profile acts of malpractice have resulted in the financial services industry being viewed as dysfunctional with many advocating increased transparency and public oversight as the necessary medicine (Hansen and Flyverborn 2015; Steffan 2009). The worldwide financial meltdown began in late 2007. As the large banks in the developed world pursued the same profit maximization strategies, they all suffered the same fate when the mortgage backed securities market collapsed (Fligstein and Habinek, 2014). While this example reflects the dark side of the business models perpetuated by financial institutions, governments began to recognise the importance of enhancing institutional oversight and surveillance (Humphrey et al, 2009). Regulatory technologies ${ }^{i}$ emerged as essential in meeting the burgeoning computational demands of compliance (Bamberger, 2013). The computerization of financial markets, has led to regulatory technologies becoming more embedded within financial trading (Schinckus 2017) and, alongside the structural and cultural changes in global financial markets, is one of the major developments within the industry since the early 1980s (Preda, 2006). Since the financial crisis, multi-level studies have emerged addressing how technology supports policies and regulations in financial markets (Fligstein and Habinek 2014). Post crisis studies on innovations which facilitate heightened regulatory supervision have focused on surveillance and disclosure technologies used by regulators to identify market manipulation by data mining for suspicious or risky transactions (Williams, 2013; Siereing et al 2017). Other contemporary studies have explored the use of blogs, social media and the crowd to facilitate trading and increase transparency of financial markets (Glaser and Risius 2017; Li et al 2017; Tiejun, and McGroaty 2017). Yet, there is an absence of work which takes a longitudinal perspective and addresses, both pre and post crisis, the relationship between regulatory technologies, embedded in trading environments, and transparency.

Within the complex 'enforcement mosaic' (Williams, 2012) of financial regulation, our empirical data shows that financial institutions have come under increasing pressure to demonstrate, through technology, their effectiveness in tackling financial misconduct in the aftermath of the high profile corporate scandals of the pre-crisis period and following the global financial crisis beginning in 2007. Both the physical and social characteristics of markets jointly influence the perceptions and behaviours of regulators, financial intermediaries and investors (Fayard and Weeks, 2007). Our study builds on prior work that shows how regulatory change and technology reshapes professional roles and relationships (Radcliffe et al, 1993; Humphrey et al, 2009). Through surveillance capabilities IT artefacts, 'might authorize, allow, afford, encourage, permit, suggest influence, block, render possible, forbid...' (Latour 2005 p.72) actions and are thereby seen to enable transparency and individual accountability. In this way, information systems play a key role in underpinning compliance by affording and constraining actions and adherence to prescribed roles (Gibson 1986; Majchrzak and Markus 2013; Zammuto et al., 2007). Technology and the affordances it forbids and creates, contribute directly to the governance of regulated economic activity (MacKenzie, 2006; Preda, 2006). Such constraints and affordances are composite of intertwined human agency, 'the ability to form and realise goals', and material agency, 'the capacity for non-human systems to act on their own apart from human intervention' (Leonardi, 2011 p.147 and 148). Institutionalist perspectives have addressed how rules, norms and logics in the form of intertwined material and symbolic elements may become encapsulated within IT artefacts (Orlikowski and Iacono 2001). Through encapsulation, 
institutional orders (regulations) may become embedded within IT systems (Scott 2003). Regulatory technologies, through the automated application of rules, have their own agency and ability to exert both constraining and constitutive effects, they co-exist with human actors and so are participants in socio-technical networks (Gozman and Currie 2014). Consequently, these technologies are implicated in the drive towards increasing levels of accountability and the corresponding 'audit explosion' where increased transparency is often touted as the remedy for organizational malaise (Mikes, 2009; Power, 2000).

To summarize, politicians, policy makers/influencers and regulators are quick to respond to public outrage by introducing new legislation to increase transparency and accountability to effect wide-ranging change in the regulatory landscape. Regulatory technologies are composed of artefacts and formulae, which project their own paths of action in order to facilitate surveillance of regulated activities (Callon and Muniesa, 2005). A perennial challenge faced by compliance officers is to keep pace with regulatory change by aligning legacy technology with new technology (Gozman and Currie, 2014). The research question we seek to answer in this paper is, 'How are regulatory technologies and compliance practices influenced and altered through changing perspectives of transparency, surveillance and accountability in pre and post crisis financial services? To answer this, we forge closer links between information systems research, the sociology of finance and the critical accounting literature (Callon and Muniesa, 2005; Mikes, 2009; Muniesa, Millo and Callon, 2007; Power, 2004).

Recognizing the diverse range of financial technologies, our research examines a specific regulatory technology in the form of an Investment Management System (IMS) deployed at eight global investment management firms with offices in the city of London, UK. We examine how asset management firms utilize the IMS to meet regulatory obligations to monitor and report on trading activities. Our motivation is not to ascertain that regulatory mandates are in place, but to unveil the complex interaction between regulators, financial firms and technology providers in negotiating appropriate levels of transparency, surveillance and accountability. These interactions occur in an uncertain yet highly regulated setting where new rules and laws are introduced to address past failures. Such rules and laws often follow rather than precede technological changes. Our longitudinal focus over a decade generates insights into the evolving role of regulatory technology within a sector that is undergoing constant political and administrative reform. Our in-depth data collection and analysis draws upon the long-term participant observation of one author over the entire period of our data collection. This enables us to develop reflective industry insights (Burawoy, 2003) that generate deep contextual knowledge of the interpretation and enactment of the various mandates emanating from regulatory bodies.

The paper is structured as follows. First, a detailed overview of the regulatory context in financial markets is presented. Regulatory technology is situated in the wider social, political and economic conditions of pre- and post-crisis financial markets. Second, we build our concepts from multi-disciplinary literature streams, including finance, information systems, management and accounting. Our research methods include details of the IMS in eight UK-based investment management firms (C.1-C.8). Third, we present our data as a pre- and post-crisis narrative about regulatory technology and emergent perspectives relating to transparency, surveillance and accountability. The discussion section synthesises the literature review with empirical data which we theorize and distil into three distinct dialectic tensions. The paper concludes by drawing insights to inform future academic enquiry, policy makers and practitioners.

\section{The Technological Dependency of Financial Markets and Compliance}

Regulator concerns about transparency relate to asymmetric information as an ongoing risk in financial markets. Information asymmetries involve one party in a transaction having 
better information than the other party does. Technology mediates the information processes at the inter- and intra-organizational levels which may lead to a 'moral hazard' (Greenwald and Stiglitz 1990) with incomplete or inaccurate information used by senior managers to obfuscate, mislead, distort, or confuse regulators and investors (Solomon, 2013). Globalization of financial services adds to the complexity (Gillespie et al., 2012; Zhang and Zhang, 2015).

Today, the role of regulatory technology is now firmly in the spotlight ${ }^{\mathrm{ii}}$, with many information technology vendors working closely with their clients to meet complex regulatory requirements (Bamberger, 2010). Compliance departments have expanded and regulatory technology presents a solution to automate labour-intensive processes and maintain audit trails to improve efficiency, precision and effectiveness of reporting and controls for greater transparency and accountability (Gozman and Currie, 2014). This study began in the pre-crisis period from 2001-2007, and continued following the post-crisis period from 2008-2013. In the pre-crisis, numerous regulatory alterations occurred in response to rapidly changing market activities. ${ }^{\text {iii }}$ During this period, private sector institutions, including accounting standards boards, auditing firms and bond rating agencies, all engaged in quasi-regulatory and surveillance activities. This was characterised by relatively weak forms of control and accountability of compliance functions, relying on international accounting standards, such as financial reporting and auditing to mitigate the problem of systemic risk in the global financial system (Arnold, 2009; Miller et al., 2008; Soin and Huber, 2013). At the same time, technology was not central to policy-making on regulation and a 'light-touch' approach to policing the financial market was in place (Black et al., 2007; Ford 2010). In the five years after the financial crisis however, the number of new and updated regulations vastly exceeded those from the earlier period. Technological automation became essential for running these new regulations and calculative methods (Itami, and Numagami, 1992; Claessens and Kodres, 2014). ${ }^{\text {iv }}$

The significant turbulence and unrest in the global financial markets is depicted as a tale of two halves. Prior to 2007, the majority of the financial scandals resulted from corporate failures with the emphasis on dishonest and self-seeking executive behaviour and accounting deficiencies which obfuscated deep routed unethical practices (Benston, 2006). The impact of the more recent crisis, however, extends beyond the collapse of a few financial corporate entities, where a systemic 'shock transmission' in the international financial industry led to global contagion (Aloui et al., 2011; De Haas and Van Horen, 2012). This financial crisis has deeper and wider implications where regulators, politicians, industry/media commentators and citizens, all seek to extend the regulatory agenda by focusing on the systemic and cultural practices in financial markets, rather than just the deviant practices by specific firms and individuals.

Technological change has completely revolutionized the financial industry (Kauffman, et al., 2014). Prior research shows that inter-connected digital networks and technologies have changed how investment houses search for opportunities in global markets (Franks et al., 2009). Implementing increased levels of automation as a form of integration, regulatory technologies help to reduce trading errors and thus, penalties and fines. These regulatory technologies enhance trading automation and exercise degrees of human and material agency (Leonardi, 2011). Increasingly, such technologies are exhibited to prospective clients as these tools potentially offer a competitive differentiator of technological reliability and robustness. Over time, regulator, investor and management attention on improving transparency through heightened levels of surveillance and accountability have increased alongside the deployment of more resources to improve internal compliance and auditing functions (Gozman and Currie, 2014; Power 2004).

\section{Rationalising Transparency, Surveillance, and Accountability}

Calls for increased, transparency and accountability often translate into heightened levels of surveillance and controls inevitably facilitated through numerous technologies and the 
affordances they create (Majchrzak and Markus 2013). Ineffective corporate governance is linked to the failure of surveillance and reporting systems where increasing 'transparency enhancement' (Blyth, 2003; p.245) has been promoted by regulators worldwide (Arnold, 2009; Williams, 2012). Regulatory and public concerns about the 'cynical greed' and malpractice within the global financial system have prevailed prior to, and following, the financial crisis (Currie, 2008, Turner, 2012a). Transparency in a regulatory context refers, to the need to externalise and make visible operational practices, investment decisions and the structure of financial products to primary stakeholders including market participants (e.g. investors and financial intermediaries) and regulators. Transparency allows us to see through 'closed doors' and obviates the need to merely trust and hope that others are acting appropriately (Roberts, 2009; Messner, 2009). Scholars have observed how in the last couple of decades there has been significant growth in auditing activities, championed by policy makers as a solution to various forms of organizational malaise (Mikes, 2009; Power, 2000; Hansen and Flyverbom, 2014). The relationship between concomitant improvements in technologies (e.g. storage and processing power) and social trends towards transparency and surveillance have been observed as being interwoven yet highly complex (Bossewitch and Sinnreich, 2013). Advocates of increasing levels of transparency rationalise that by making practices, products and decisions less opaque information asymmetries are reduced (Solomon, 2013). The assumption is that firms and individuals are more easily held accountable for their actions and sanctioned accordingly (Sewell and Barker, 2001). Individuals take responsibility for their actions and the capability of others to judge where misconduct has occurred and apply necessary penalties is strengthened (Messner, 2009). In order, to achieve the desired level of transparency and accountability those acting in a policing role, surveil individuals and organizations (Iedema and Rhodes, 2010). Surveillance may take many different forms including reporting outcomes to regulators, those organizing markets (e.g. stock exchanges) and auditors. Surveillance is mediated through various types of regulatory technologies and include templates, reports and mathematical models (Hansen and Flyverbom, 2015). Integral to the surveillance process are calculative technologies into which are embedded pre-negotiated methodologies and tiers of similarity and difference, which are aggregated into common metrics and rankings. Calculative devices reflect the views and biases of those who design the measurements and metrics and so regulatory technologies are also not objective (Bamberger, 2010; Hansen and Flyverbom, 2015: Itami and Numagami, 1992). Regulatory technologies create their own worldview that influences the perceptions of those decision makers the system was created to inform (Heidegger, 1954; Kane, 1981). These observations are not unique to IS scholars.

The transparency literature observes an overreliance on systems of measurements and predefined thresholds, such as accounting and auditing practices, which presuppose categories of relevance, methods for monitoring outcomes and standards of behaviour (Strathern, 2000). Critiques suggest that such an approach creates, a new ideal of 'self-control and self-observation' through organizational hierarchies, processes and systems of internal control and risk management (Power, 2007; Roberts, 1991). Such formal accountability may have the effect of individualizing and normalizing actors as through increased visibility they may be, 'compared, differentiated, hierarchized, homogenized and excluded' and so produce, 'a defensive or assertive preoccupation with the self and how the self is seen' (Roberts, 2001; p.1552). Some scholars have proposed that conventional systems of control and measurement may hinder appropriate levels of mutual responsibility. The removal of such controls and related hierarchies may create a 'socializing' process of accountability and build a, 'sense of the interdependence of self and other', and so generate alternative understandings of organizational reality (Gray, 2002; Roberts, 1991; 2001 p.1554; Shearer, 2002; Messner, 2009).

During the financial crisis, systems for self-governance were increasingly questioned (Greenspan, 2008; Roberts and Jones, 2009). Some commentators viewed a lack transparency as 
a key shortcoming, as information relating to asset securitizations and derivatives, for example, was insufficient to allow investors to assess the values and risks of securities (Barth and Landsman, 2010). The paradox was that others suggest transparency contributed to the financial crisis as rules that were intended to underpin investor confidence accentuated investor panic. As it became clear that Northern Rock was failing, the transparency rules prevented the Bank of England from discretely intervening to prevent the 'run' on the bank. In this way, transparency rules and obligations construct their own performativity (Roberts, 2009; Callon, 2007).

\section{Regulatory Paradoxes: Ethics, Rules and Principles}

Corporate failures and financial irregularities (e.g. Worldcom, Enron) intensified a culture of compliance, increasing surveillance and ethical behaviour (Awrey et al., 2012). The view that individual firm success is incumbent on surveillance of the financial industry under the notion that 'we are all in it together' is a powerful message as regulatory bodies recognize the need for cooperation among key financial institutions to improve compliance policies across the sector. The boundary-spanning role of regulatory technology to enhance surveillance of financial activities and encourage better ethical practices is important for several reasons. Technology can provide those responsible for market oversight with significant quantitative data for decisionmaking to meet regulatory conditions and facilitate governance (Tan, 2014). Though often perceived as a form of coercion, surveillance and monitoring practices provide a disciplining form of power able to construct conformity in individuals (Collinson, 1999; Power 2000; Strathern, 2000) encouraging self-determination, reflective, inventive and creative practices as the foundation of ethical practice (Barratt, 2008; Bernauer and Mahon, 1994). This suggests that surveillance is an instrument of managerial coercion and control to shape peoples' behaviour (Sewell and Barker, 2001) which may lead to ethical paradoxes (Iedema and Rhodes, 2010).

Surveillance manifested in regulatory technology to enhance transparency and accountability through performance measurement aims to prevent behaviours derived from selfinterest (Gozman and Currie, 2014; Siereing et al 2017; Williams, 2013). Paradoxically, technological systems of surveillance and measurement, embedded within controls and risk management practices, may also increase individual self-interest as they internalise measurements of success and equate their own worth to their position within the hierarchy (Power, 2007; Roberts and Jones, 2009). The frequent and, in some cases, fateful outcomes of financial traders acting in their own self-interest and flouting regulatory rules is an example of this behaviour (Krawiec, 2000).

Ethical behaviour requires a level of self-determination beyond merely just resisting or conforming to regulation and related systems of measurement. Ethical practice is about the emulation of regulation and discipline through establishing reflective, inventive and creative ways through which individuals can relate to the world (Bernauer and Mahon, 1994). A key element of reflective practice is the ability to question, clarify and challenge cultural views and expectations, to build mutual understanding, friendship, loyalty and reciprocal obligations (Gray, 2002; Roberts, 1991; 2009; Power, 2007). We do not argue that ethical decision-making represents the cultural side of regulatory compliance while surveillance represents the material constraints on individuals embedded within formal controls and technology. Rather, we examine tensions that exists between the ideological expression of ethics and surveillance combined with the practice of introducing technology to meet regulatory mandates. These concepts are not mutually exclusive but exist as a tension between existing and desired outcomes (Alvesson and Deetz, 2000 p.171). In financial regulation, this tension plays out through attempts to build a culture of compliance, with seemingly conflicting messages from rules-based and principlesbased ideologies (Ford 2010). 
Achieving an ideal state of transparency may paradoxically undermine measures to increase accountability. The degree to which it is ethical to hold an individual accountable when they may not be fully cognisant of their decisions is the subject of much debate (Butler, 2005; Messner, 2009). Where the transparency of investment banks and asset management houses acting as intermediaries to ensure the safeguarding of investors' interests is opaque, this type of information asymmetry means that investors have little understanding of the securities they are buying, the firms issuing them, and the activities of financial intermediaries (Williams, 2012). Regulatory technology may further complicate this process, particularly as recent forms of financial trading remove the individual as the primary decision maker. Indeed, technological innovations such as AI and blockchain are further removing the induvial from the transaction. Technology thus facilities and constrains human intervention in financial trading.

In summary, regulators have publicly responded to successive financial failures by calling for more surveillance, transparency and accountability, albeit providing limited guidance to financial firms. Regulators support technological intervention to automate the compliance function, as they see this as a way of achieving greater operational efficiency within a wider landscape of increasingly fragmented and complex global financial markets. Rationalizations of surveillance, transparency and accountability, viewed by regulators as mutually reinforcing and inter-related, create expectations of optimal outcomes, when embedded in regulatory driven technological affordance (Lenglet, 2011). Building on existing work on regulatory technology (Williams, 2012; Williams, 2013; Currie 2008; Gozman and Currie, 2014), we question assumptions of the neutrality of regulatory technology, inherent in related dialogues between stakeholders, by offering theoretical and empirical insights from the introduction of an investment management system in eight financial firms.

Surveillance, transparency and accountability theorized as ideological and material concepts help to frame our understanding of how financial firms, while contributing to discussions shaping financial regulation, are also required to embed these mandates and rules into their own financial trading systems. Our study does not assume that regulatory technology improves surveillance activities, increases transparency of financial reporting, or enhances the accountability of managers and traders. Instead, we view regulatory technology as a material artefact within a complex socio-technical system (Somerville et al., 2012, Cliff \& Northrop, 2010), subject to changing policy and strategic priorities of regulators and financial firms. Such priorities are negotiated through complex dialogues between, regulators, financial intermediaries, investors, technologists and other stakeholders. Combining concepts from the literature review with our empirical data, we inductively build a multi-level framework (Figure 1) which embeds different perspectives regarding, transparency, surveillances and accountability to illustrate the complex relationships between regulatory technologies and stakeholders. Our research adopts a multi-level methodological approach combining macro and meso level constructs with micro level analysis (Perrow, 1985). These interconnected levels treated separately provide a degree of analytical clarity in organizing our empirical data on financial markets. 


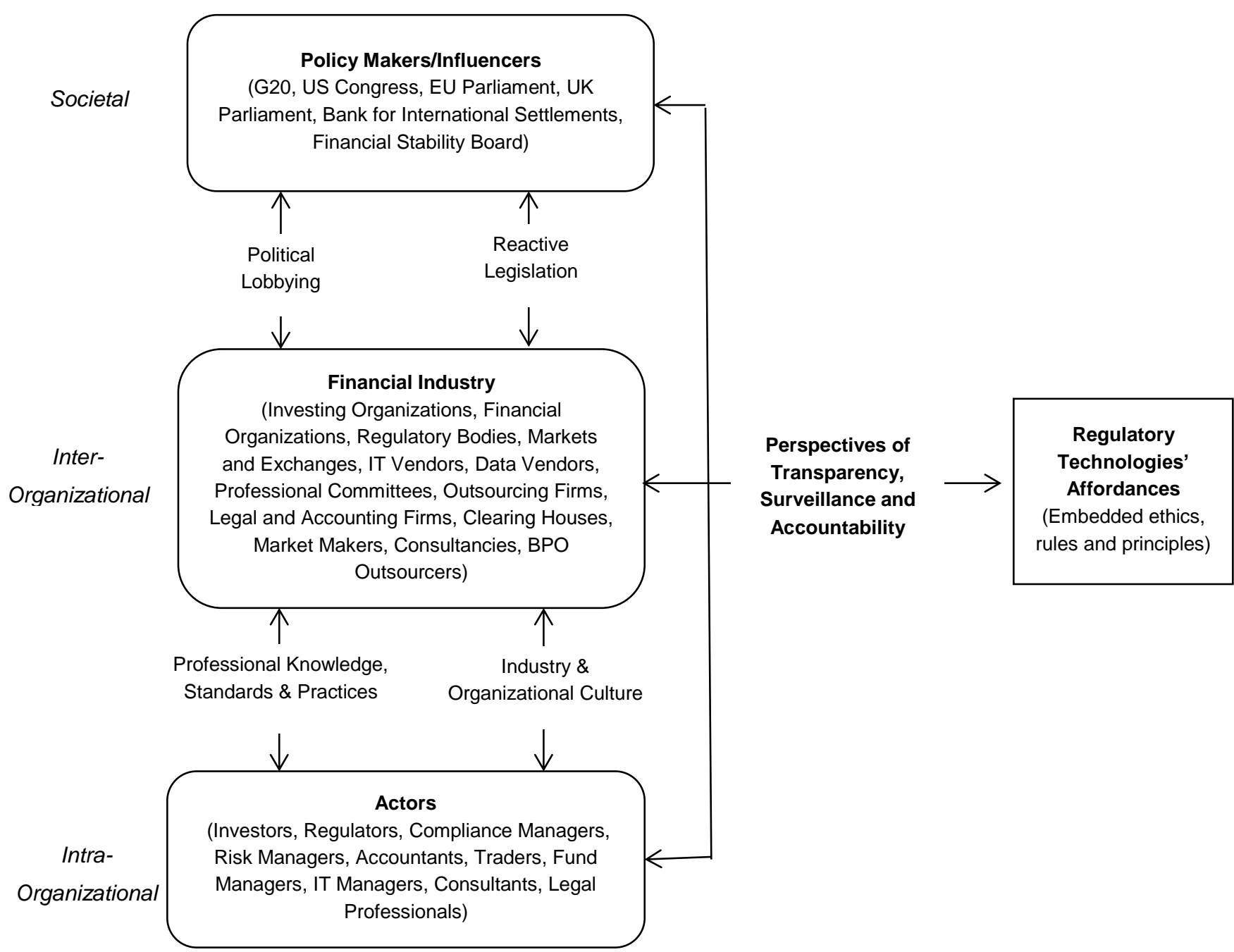

Figure 1. Conceptual Model of Transparency, Surveillance and Accountability

\section{Research Method}

To gain deep insights into the effects and processes of the role of regulatory technology in meeting regulatory and compliance requirements we selected a process-oriented, longitudinal, multiple case method. Our interest was to observe the implementation of a regulatory technology across eight sites over an extended period of time. These organizations offer a range of financial products that expose them to a variety of regulatory obligations. Specifically, each deployed an investment management system (IMS) for trading a mix of equities, derivatives, fixed income and currency securities. A multiple case method allows for inductive theory building through the selection of cases which provide rich empirical descriptions of the phenomena under consideration (Eisenhardt, 1989; Eisenhardt and Graebner, 2007). Our intention was not to compare and contrast the regulatory and compliance strategies of each company, but to provide a more nuanced account of how surveillance, transparency and accountability are embedded into regulatory technology to meet compliance mandates. 


\section{The Investment Management System}

The IMS originated in the U.S as a system to automate compliance regulations. After almost thirty years of development, it manages trades at hundreds of companies located in over 40 countries. Regulations and laws, defined by policy makers and enforced by regulatory bodies are interpreted by compliance executives and codified into rules which are then associated with an investor's account. The compliance engine, which checks if the relevant rules for that account are met, can be run at four different times during the life-cycle of an order. The first is before any trading activity occurs. Every compliance value is calculated and used for the start of day reports. The second is when a fund manager sends an order to the trading desk. Here, the system checks that all proposed changes meet every rule associated with the orders. A third compliance check can be made by a trader who is 'working' an order, for example checking that price movements will not push the trade out of compliance. The last check is before an order is exported out of the IMS, where factors that were not known when the order was initially created, such as the broker used to fulfil the trade, can be evaluated.

The IMS provides a dashboard to view compliance rules, trade information, asset details, pricing, and other related trades relevant to the transaction being viewed. The system generates historical and trend reports (for as far back as the data has been saved) in order to measure and compare different compliance violations over time. At the start of every day, the compliance team looks at the reports and decides the actions to bring financial positions back to agreed levels. For example, a breach might occur after stock price movements, and so a fund manager will need to sell a certain value of a security to reduce the portfolio's holdings to pre-defined levels. If a breach occurs during the day when a user has run the compliance engine the system can be configured so that the appropriate people are informed, and that the necessary steps are taken to resolve this issue. The system provides auditable records on every transaction to show how and when breaches are managed and so provide performance-monitoring capabilities. The compliance tests are formulaic and include one of the following elements: exclusion (e.g. no tobacco); counts (e.g. no more than five French securities can be held); values (e.g. calculate a number and then use this in another test) and logic (e.g. if-then-else type tests). Even for simple rules, translating what has been written using 'English-like' syntax into the code that is executed adds further layers of calculative complexity.

\section{Research Design}

Longitudinal studies are appropriate when the focus is on the interconnections between the context, content and processes of change over time (Pettigrew, 1990; Symon and Cassell, 2012). This method allows the investigation of the interplay between the outer context of economic, social, political, and sectoral factors and the inner organizational context, where compliance practices are formulated through internal structural, cultural, and political environments. This approach allowed us to overcome common shortcomings in retrospective research designs limited to snapshot, time-series data, which may result in accidental or purposeful misrepresentation and fail to capture immediate and distant experiences (Golden, 1992; Pettigrew, 1990).

The initial study explored the implications of corporate failures on regulatory technologies and focused on how the IMS was used to support compliance practices. As new regulations were introduced, the study was extended to investigate the impact of these important changes. Following the beginning of the financial crisis in late 2007, we continued to investigate how the IMS was adapting to regulatory responses to the crisis. Table 1 summarizes the data sources utilized. 


\begin{tabular}{|c|c|c|}
\hline & Data Source & Purpose \\
\hline \multicolumn{3}{|l|}{ Primary Data: 2001-2013 } \\
\hline $\begin{array}{l}\text { Interviews with key } \\
\text { individuals engaged in } \\
\text { compliance practices }\end{array}$ & $\begin{array}{l}\text { Representatives from: } \\
\text { - IMS Vendor } \\
\text { - UK based Asset } \\
\text { Management Firms } \\
\text { - } 3^{\text {rd }} \text { Party Consultancies } \\
\end{array}$ & $\begin{array}{l}\text { To provide rich interpretations of the impact of } \\
\text { regulatory change on the socio-technical compliance } \\
\text { environment within participant financial } \\
\text { organizations and how they have evolved over time. }\end{array}$ \\
\hline \multicolumn{3}{|c|}{ Secondary Data: 2001-2013 } \\
\hline News articles & $\begin{array}{ll} & \text { BBC } \\
- & \text { Economist } \\
- & \text { Financial Times } \\
\end{array}$ & $\begin{array}{l}\text { To provide overview of key economic events and } \\
\text { failures }\end{array}$ \\
\hline Regulatory mandates & $\begin{array}{ll}- & \text { EU Directives } \\
\text { - } & \text { US Acts of Congress } \\
\text { - } & \text { UK Regulator's Handbook } \\
\end{array}$ & $\begin{array}{l}\text { To provide understanding of specific areas of } \\
\text { regulatory change and associated rules }\end{array}$ \\
\hline $\begin{array}{l}\text { Commentary from Legal } \\
\text { and Accounting Firms }\end{array}$ & $\begin{array}{l}\text { - White papers } \\
\text { - Websites }\end{array}$ & $\begin{array}{l}\text { To support understanding of the interpretation of } \\
\text { regulatory mandates and the associated impact on } \\
\text { organizations }\end{array}$ \\
\hline Marketing Materials & $\begin{array}{l}\text { - IMS website and marketing } \\
\text { pamphlets } \\
\text { - Financial organization } \\
\text { websites and annual reports }\end{array}$ & $\begin{array}{l}\text { To provide insight into the products and services } \\
\text { being offered by financial organizations } \\
\text { To provide insight into the infrastructure, } \\
\text { outsourcing and consulting services offered by the } \\
\text { IMS Vendor }\end{array}$ \\
\hline
\end{tabular}

Secondary Data: 2008-2013

\begin{tabular}{|c|c|c|}
\hline $\begin{array}{l}\text { White Papers, press releases } \\
\text { and speeches }\end{array}$ & $\begin{array}{l}\text { - Regulator's white papers } \\
\text { and press releases } \\
\text { - Speeches from key policy } \\
\text { makers/influencers }\end{array}$ & $\begin{array}{l}\text { To provide insight into policy changes and } \\
\text { associated motivations for changing regulatory } \\
\text { structures. }\end{array}$ \\
\hline
\end{tabular}

\section{Table 1. Primary and Secondary Data Sources}

The study was conducted over a twelve year period from 2001-2013. Using a semistructured interviewing technique, in-depth interviews were carried out at the systems vendor site, in addition to the client sites, all of which were long term users of the IMS. A multi-case research design allows for both external and internal validity (Leonard-Barton, 1990). External validity was achieved by adopting a multiple or collective case study approach allowing 'literal replication' through 'typical case' sampling (Patton, 1990; Yin, 2009). This approach allowed for internal validity by allowing close inspection of the context and causes of changes in compliance practices. Internal validity was achieved by considering different empirical data sources. Scope, depth and consistency was enabled by discussing key concepts, constructs and terminology with each of the informants and triangulating the findings across primary and secondary data sources (Flick, 1998; Seale, 1999). The financial organizations were selected with the cooperation of key informants within the IMS Vendor, including the IMS Relationship Manager. Focusing on identifying replicable cases of system use (Yin, 2009), selected organizations used the IMS to manage similar financial products and services and so had comparable levels of regulatory exposure. Correspondingly, the data collected addressed similar topics of regulatory change and so allowed for cross-case comparisons (Miles and Huberman, 1994). Our study does not explicitly seek to present contrasting and comparative compliance 
practices adopted by different organizations. Instead, we draw from collective interpretations of experiences across these organizations to illustrate a rich tapestry of regulatory change and technology (Patton, 1990). Table A1 in the appendix outlines the companies selected, as of 2013.

The 'essential task of theory building here is not to codify abstract regularities but to make thick description possible; not to generalize across cases but to generalize within them.' (Geertz, 1973 p.25-26). Thus, at the minimum this study allows for generalizability across the user community of the IMS studied. The findings are applicable to users of regulatory technologies and IMS provided by other vendors, which all function similarly through a rule based approach to automating compliance. The fact that many vendors of similar systems are adapting their offerings to overcome common issues, such as data quality and availability, supports the view that vendors and users of these systems are facing similar issues to the ones identified in the study.

The IMS's customer base, the focus of our study, are limited to organizations which participate in the 'buy-side' of the investment banking industry, the buying and selling of securities for investment purposes on the behalf of clients and so the study's findings are limited to this specific area of the industry. As post-crisis regulations come into force the IMS plays a pivotal part in complying with new mandates. Its role is limited to managing compliance in regulatory obligations which require organizations to apply limits on trading positions and monitor trades.

\section{Data Collection}

Across the participant organizations, the strategy for primary data collection involved interviewing a diverse range of stakeholders (Miles and Huberman, 1994; Silverman, 2001). All interviews were transcribed and managed by NVivo software. Semi-structured interviews have previously proved successful in providing the necessary depth to explore complex and dynamic regulatory phenomena (Tsatsou et al., 2009). The semi-structured approach allowed the flexibility to pursue new topics as the discussion evolved and also as regulatory responses to the crisis emerged and became better defined (Kvale and Brinkmann, 2009; Punch, 2005). An objective was to elicit views and comments from interviewees engaged in the adoption and implementation of the IMS at client sites. Within the financial organizations, trading professionals, compliance and systems experts were interviewed all of whom had responsibilities around the IMS. At the Vendor site, senior systems consultants and relationship managers were interviewed. This was especially insightful as collectively they had much experience of implementing IMS and dealing with clients, post and pre crisis. Third party consultants working within the financial organizations on remediation projects were also interviewed. Table 2 summarizes the interviews conducted. 


\begin{tabular}{|c|c|c|}
\hline & $\begin{array}{l}\text { No. of } \\
\text { Interviews }\end{array}$ & Purpose \\
\hline \multicolumn{3}{|l|}{ IMS Vendor } \\
\hline IMS Consultants (7) & 24 & $\begin{array}{l}\text { To provide insight into different implementations and upgrades of } \\
\text { the IMS undertaken over time }\end{array}$ \\
\hline IMS Relationship Managers (3) & 20 & $\begin{array}{l}\text { To provide insight into the changing business requirements of the } \\
\text { Vendor's clients }\end{array}$ \\
\hline \multicolumn{3}{|l|}{ Financial Organizations } \\
\hline Compliance Managers (8) & 64 & $\begin{array}{l}\text { To provide user insight into the impacts of regulatory change on } \\
\text { financial organizations over time }\end{array}$ \\
\hline Chief Information Officer (4) & 10 & $\begin{array}{l}\text { To provide insight into the impact of regulatory change on IT } \\
\text { strategies }\end{array}$ \\
\hline Finance Director (2) & 8 & $\begin{array}{l}\text { To provide insight into the impact of regulatory change on } \\
\text { financial controls }\end{array}$ \\
\hline Traders (8) & 16 & $\begin{array}{l}\text { To provide user insight into the impact of regulatory change on } \\
\text { investment strategies, trading practices and supporting } \\
\text { technologies }\end{array}$ \\
\hline IT and Project Managers (9) & 24 & $\begin{array}{l}\text { To provide technical insight into the impacts of regulatory change } \\
\text { on financial organizations projects, processes, technical } \\
\text { architectures and strategies }\end{array}$ \\
\hline $3^{\text {rd }}$ Party Consultants (4) & 12 & $\begin{array}{l}\text { To provide insight into the management structures and practices } \\
\text { which may enhance remediation efforts in financial organizations }\end{array}$ \\
\hline
\end{tabular}

Table 2: Interview Sources, 2001-2013

\section{Participant Observation and Data Analysis}

It is suggested that the purest form of longitudinal field study is participant observation (Leonard-Barton, 1990). The ability to closely examine underlying constructs contributing to changing events is particularly valuable in longitudinal research (Siggelkow, 2007). Indeed, the third author's knowledge base of contemporary regulatory, technological and industry developments throughout the period of the study allowed the investigation of complex change and how key actors' perceived and responded to such changes (Becker, 1958). Overall, the participant observation element of the research study considerably enhanced the research by providing access to and understanding of key underlying constructs (Becker, 1958; DeWalt and DeWalt, 2012; Schwartz and Schwartz, 1955). This co-author's role as the IMS Vendor's most senior Relationship Manager enabled access to and visibility of regulatory technologies and how they were being implicated in social responses to regulatory phenomenon. Access included numerous individuals working for a variety of financial organizations. We noted observations about the possibility of bias from participant observation (DeWalt and DeWalt, 2010, Drury and Scott, 2001). However, a level of bias in all research enquiry is inevitable (Schwartz and Schwartz, 1955) as all researchers have predispositions which they carry with them at all times. To mitigate the problem of bias, each client was asked to verify the data used in this paper and provide detailed comments about any miss-representation. A key strategy employed by the Vendor was to adopt a critical perspective of their own IMS and acknowledge these deficiencies as they became apparent and then to incorporate necessary changes into future software release.

This study provides detailed context-specific data. Our research design seeks to trace common paths of regulatory change on compliance practices, within a research space theoretically framed by concepts such as surveillance, transparency and accountability (Avgerou, 2013). Correspondingly, our findings relate to a specific research problem - how to use regulatory technology to meet the conditions of financial regulation. Our analytical approach was inductive, multistage and irrelative in design (Guest et al., 2012). Data analysis was conducted through long established interpretive techniques for analyzing data through the recursive 
identification of patterns, first through categorization and then abstraction (Guest et al., 2012; Miles and Huberman, 1994; Saldana, 2009; Silverman, 2001; Symon and Cassell, 2012). Primary and secondary data were closely reviewed to determine points of importance and interest. Common themes were identified and categories assigned. Thus, complex and voluminous data sets were simplified through the adoption of simple categories (Punch, 2005). The analysis adopted a three cycle approach to coding with each cycle consisting of multiple iterations through the data. The first cycle adopted a 'Descriptive Coding' approach for summarizing segments of data. This method is appropriate for inductive studies utilizing semi-structured protocols (Saldana, 2009). This approach requires the application of a content phrase to a segment of data representing a topic of inquiry, for example, 'Use of Spreadsheets', 'Use of Automated Rules' and 'Increased Compliance Costs'. These content phrases relate to specific compliance practices which have evolved as a result of the shifts in the regulatory environment. The second cycle adopted a 'Pattern Coding' approach to identify major themes. This approach builds on the first cycle of analysis and organizes vast amounts of material into a more meaningful and parsimonious unit of analysis (Miles \& Huberman, 1994). Examples of such codes include our key concepts used in this study, surveillance, transparency and accountability. The final cycle involved a careful analysis of our data across the two phases (pre and post financial crisis) of our study.

By adopting an approach which moves from categorizing discrete compliance practices to abstract themes and then subsequently categorizing such themes against different levels of analysis and periods of time and we seek to apply a form of research which is both contextual and processual, both vertical and horizontal (Pettigrew, 1985; 1990). At the vertical level, our study explores the interdependencies between the societal (regulatory environment) and organizational (firm) level compliance practices. At the horizontal level, the study explores the sequential interconnectedness and historical contingencies of pre and post crisis regulatory phenomena, and its impact on compliance practices underpinned by technology. Our empirical data allowed us to gain a deeper understanding of how regulatory compliance changes over time as a result of societal, organizational and technological factors. We present the ideological and material changes in the financial industry in two distinct eras, which we label the pre- and postfinancial crisis.

\section{Findings}

Over a twelve-year period starting in 2001, fundamental changes were observed in the policy and practice of financial regulation. Technology became more critical in this period as regulators, industry practitioners and investors wanted to avoid further financial shocks in global financial markets that were increasingly fragmented and inter-connected (Funk and Hirschman, 2014). Over this time span, compliance shifted from a siloed, mechanistic activity to an integrated and company-wide activity. In the pre-crisis, compliance systems were seen as a 'nice to have' technology, desirable but not critical to the compliance function. This changed to a 'must have' following the financial crisis, as clients increasingly became cognizant of public and regulators' calls to increase transparency. Post-crisis investors demanded robust and best-in-class systems to monitor and account for all trading activities. Table 3 combines the data from the pre- and post-crisis to show how perspectives around technological policies, priorities and practices shifted over time. A discussion follows by presenting empirical themes and interview data in chronological order on the pre- and post-crisis periods. 


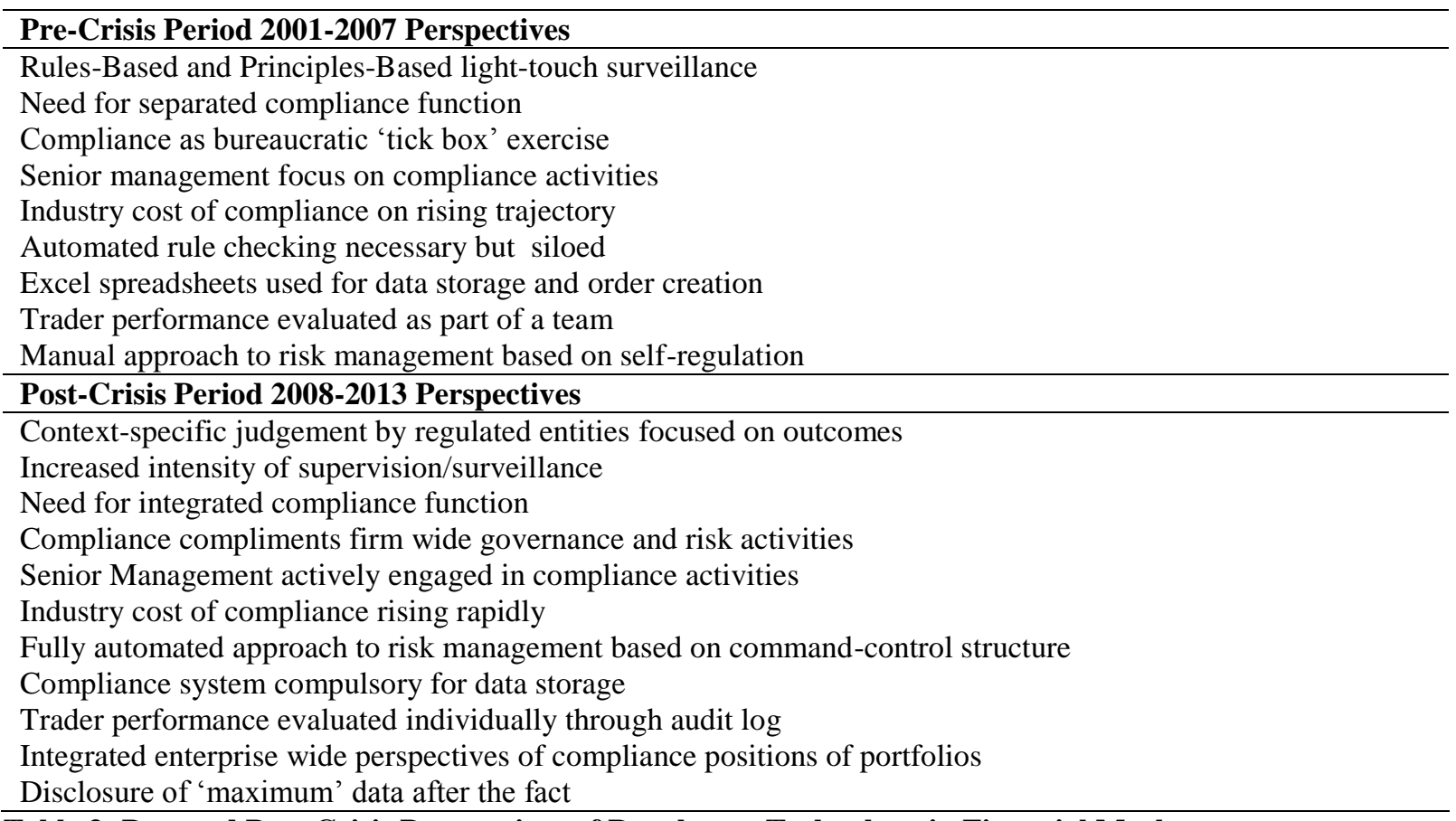

Table 3: Pre- and Post-Crisis Perspectives of Regulatory Technology in Financial Markets

\section{The Pre-crisis Period: 2001-2007}

The emerging themes from our interview data from the eight financial firms in Table 4, provide the essence of how regulatory technology was increasingly embedded into the compliance function as a result of financial regulation. 
Selected Pre Crisis Period Quotes 2001-2007

\begin{tabular}{|c|c|c|}
\hline Item & Theme & Interviewee Quote \\
\hline A. 1 & $\begin{array}{l}\text { New regulations as } \\
\text { resource intensive } \\
\text { 'tick box' exercises }\end{array}$ & $\begin{array}{l}\text { 'While SOX may resolve some problems, I think it will generate others. What I have seen } \\
\text { so far is that managers are more concerned to tick the boxes rather than worry about some } \\
\text { of the more fundamental lapses in compliance. Whilst SOX has been designed to improve } \\
\text { compliance and put an end to financial fraud and mal-administration, the cost of } \\
\text { compliance has been enormous. Many of our senior managers have had to divert their } \\
\text { attention to respond to the demands of SOX, rather than to the demands of their major } \\
\text { clients.' (Compliance Manager in C.1) }\end{array}$ \\
\hline \multirow{2}{*}{ A. 2} & $\begin{array}{l}\text { Regulatory } \\
\text { technologies } \\
\text { increasing } \\
\text { responsibility and } \\
\text { accountability }\end{array}$ & \multirow{2}{*}{$\begin{array}{l}\text { 'Although technology has always been part of this industry, a lot of the business has been } \\
\text { done through face-to-face meetings. But the scandals of Barings Bank, and more recently, } \\
\text { WorldCom and Enron, have put compliance at the top of the management agenda. The IMS } \\
\text { implementation will certainly improve our compliance processes, but it will also increase } \\
\text { our responsibility and accountability to some extent. Somefund managers and traders have } \\
\text { criticized the system because they think it forces them to change the way they do } \\
\text { things... and nobody likes to change what they are used to.' (IMS Project Manager in C.1) }\end{array}$} \\
\hline & $\begin{array}{l}\text { Regulatory } \\
\text { technologies } \\
\text { changing embedded } \\
\text { practices }\end{array}$ & \\
\hline \multirow{2}{*}{ A. 3} & $\begin{array}{l}\text { The introduction of } \\
\text { regulatory } \\
\text { technologies to } \\
\text { prevent errors }\end{array}$ & \multirow{2}{*}{$\begin{array}{l}\text { 'The compliance system was introduced to stop human error. One fund manager } \\
\text { complained recently that the 'Buy' and 'Sell' buttons were too close together, and they } \\
\text { could easily press the wrong one. Others want a pop-up box to appear after clicking the } \\
\text { 'Send to Trading' button, asking if they had meant to press the button.' (IMS } \\
\text { Implementation Manager in C.4) }\end{array}$} \\
\hline & $\begin{array}{l}\text { The introduction of } \\
\text { regulatory } \\
\text { technologies created } \\
\text { new types of errors }\end{array}$ & \\
\hline \multirow[t]{2}{*}{ A. 4} & $\begin{array}{l}\text { The introduction of } \\
\text { regulatory } \\
\text { technologies reduced } \\
\text { creativity, personal } \\
\text { judgment and risk } \\
\text { tacking }\end{array}$ & \multirow{2}{*}{$\begin{array}{l}\text { 'I am probably one of the oldest traders at this firm, being just over } 40 \text { years old. I have } \\
\text { witnessed major technological changes in the industry over the past } 20 \text { years. Sometimes I } \\
\text { think that our creativity and judgment has been subsumed under what is seen as } \\
\text { technological progress. In the past, if you made a mistake, it might not have been picked } \\
\text { up immediately. When it was found, you could probably correct it without anyone knowing } \\
\text { about it. Now there is a massive audit trail, so you are far more careful about the trades } \\
\text { you execute. The job is definitely less enjoyable as you feel under constant surveillance!' } \\
\text { (Senior Trader in C.3) }\end{array}$} \\
\hline & $\begin{array}{l}\text { Regulatory } \\
\text { technologies changed } \\
\text { behaviours through } \\
\text { surveillance and } \\
\text { accountability }\end{array}$ & \\
\hline \multirow[t]{2}{*}{ A. 5} & $\begin{array}{l}\text { Surveillance and } \\
\text { monitoring } \\
\text { capabilities changed } \\
\text { organizational culture } \\
\text { by monitoring } \\
\text { individual } \\
\text { performance }\end{array}$ & \multirow{2}{*}{$\begin{array}{l}\text { 'Prior to the compliance system [IMS] being installed, senior managers had much more } \\
\text { freedom to execute decisions about buying and selling stock. We recently had to dismiss } \\
\text { one of our senior managers because he had broken several rules and this led to us } \\
\text { compensating the client. Over time, people will just have to get used to the fact that their } \\
\text { decisions are being recorded, monitored and scrutinized. This will lead to further changes } \\
\text { in the culture of investment banking.' (Compliance Manager in C.8) } \\
\text { 'The trading function has changed enormously since the early 1980s. There is more focus } \\
\text { on governance and compliance now, but this is becoming more challenging as the financial } \\
\text { markets have been de-regulated with more financial products needing to be monitored. } \\
\text { Technology is constantly evolving, and meeting regulators' demands is becoming more } \\
\text { costly to financial firms' (IT Director in C.4) }\end{array}$} \\
\hline & $\begin{array}{l}\text { Regulatory } \\
\text { technologies used to } \\
\text { monitor performance } \\
\text { and sanction } \\
\text { individuals }\end{array}$ & \\
\hline A. 6 & $\begin{array}{l}\text { The use of multiple } \\
\text { regulatory } \\
\text { technologies acted to } \\
\text { hinder transparency }\end{array}$ & $\begin{array}{l}\text { '[Regulators] now want to have a complete view of a portfolio and therefore, every } \\
\text { transaction has to be on one system and what they will do is use the [IMS] as the means } \\
\text { and mechanism for recording all the positions. You've got big companies who have } \\
\text { multiple [IMS] systems and therefore, do not have a clear view of their entire book of } \\
\text { records.' (IMS Relationship Manager for C.1-8) }\end{array}$ \\
\hline
\end{tabular}

Table 4: Pre-Crisis Period Themes and Data 2001-2007

Prior to the pre-crisis period, investment management companies typically used their financial systems to value portfolios and run compliance checks. The major obstacles encountered were around the cost and time taken to add new and often complex rules that were only checked at the end of the trading day. During the 1990s, PC based compliance and trading systems developed to fill this gap and became a legitimatized platform to handle new complex 
regulatory obligations. Such systems were seen as providing an architecture, which would facilitate increasingly complex products traded over diverse locations in larger volumes. Trading in a global and fragmented market presented financial firms with new challenges in managing large data sets. The head of compliance at C.1 said that 'it is just not possible to accurately check every rule because of the quality of data that is brought into the system. We get thousands of alerts every day because of missing data'. Not only was the additional data costly (the IT manager at C. 4 said that a key data set cost $£ 50 \mathrm{k}$ each year) but accurately mapping this into the system was problematic as the data was not standardised and often came from multiple sources.

Following a series of high profile accounting scandals (Enron, Arthur Anderson, Worldcom, Tyco, Xerox, Adelphia, Global TelLink and HealthSouth) 2002 saw the introduction of new regulatory mandates in the form of the Sarbanes-Oxley (SOX) Act. This represented the most sweeping changes since the Securities and Exchange Act of 1933 and focused on the accuracy of corporate account records and the controls thought necessary to provide well-run organizations. The most contentious part of SOX was section 404, which in less than 75 words gave vague and non-prescriptive requirements for all publicly traded companies to develop internal controls for assuring the accuracy of financial reports and disclosures and for external auditors to report on the adequacy of those controls. Consequently, the role of IT in complying with regulations became more critical, requiring senior IT professionals to pay close attention to meeting new regulatory obligations. In contrast, section 406 received less attention and required firms to establish an ethical code, outlining the conduct of senior financial and executive officers. It aimed to address the ethical failures of Enron and others by stipulating that firms provide a written code of ethics published via the firm's website or annual reports. New regulations perceived to be costly and diverting key people from other important tasks were unwelcome in many firms. Rather than providing an opportunity to encourage new cultural values and professional norms, some respondents viewed new regulations as just another bureaucratic exercise (A.1).

The pressure to change working practices and business processes to comply with SOX was to conform to current compliance policy rather than improve business operations. Compliance described as a 'bureaucratic exercise' in the eight investment management firms, was further seen as ' $a$ cost of doing business'. The regulatory technology in the form of the IMS gave oversight and accountability to trading decisions (A.2). Publicly, senior management said compliance had become 'a top priority', as part of an overall policy to improve governance practices. Coupled with the coercive mechanisms of regulation in the form of administrative controls, senior managers repeated their interest to show investors and shareholders that cultural changes were taking place as the technology was a surveillance tool to record all trading activities.

During this period, the compliance function was subservient to the trading desk. One compliance manager, in C.3, described tensions between compliance and the traders as a 'big bugbear.' The attitude of the traders was, 'let us focus on our job and just give us a chance to run the business'. A trader for company C.2 noted that good compliance was about, 'protecting the business not preventing it to succeed' and that if, 'compliance officers were acting as obstacles to the business they were not doing their jobs properly.' Conversely, a compliance executive for C.5 noted that, in his opinion, 'people need to understand that there is a correlation between compliance and quality' and that, 'a transaction should not be viewed as successful unless it is also compliant.' Tensions were apparent between a surveillance culture with punitive measures against compliance breaches and one that fostered practice-based learning with mistakes tolerated if not accepted. One compliance manager for C.7 reinforced this point by suggesting that, the 'learning culture' where people do not apply blame, is in contrast with the 'blame culture' which 'holds individuals accountable for their actions'. Irrespective of whether 
errors were deliberate or not, a less formalized governance structure existed that relied on a manual checking process, prior to the introduction of the IMS.

While the IMS reduced manual errors through automation, its design and users' lack of familiarity with the system led to other errors, creating new governance challenges (A.3). Following the introduction of new regulatory standards, individual action and behaviour was constrained through conformance to the governance and control structures configured in the IMS. As well as reducing human error, senior management also perceived regulatory technology as a way to control individual behaviour and reduce inappropriate risk taking. The introduction of the IMS facilitated the imposition of new rules and regulations upon the workforce to constrain the freedom and autonomy of those using the system (i.e. fund managers, traders and compliance officers (A.4 and A.5). Though the IMS introduced new governance practices and highlighted compliance breaches, senior individuals within the front office could overrule the compliance department and undermine the system, as they retained the balance of power. Furthermore, despite the imposition of legal and regulatory pressures to enforce new governance structures, abrupt changes to existing practices and procedures tended to generate confusion and correspondingly reduce the level of efficiency of the IMS.

Not one of the eight companies surveyed had a single IMS. Instead, they looked to integrate the best-of-breed systems for activities such as equity trading, derivative modelling or compliance calculations. This enabled them to trade more complex products (such as swaps) whilst meeting many of the new regulatory requirements. The rigid configurability and limited affordances, that gave the system its ability to provide transparency and build confidence with regulators, was seen by some, as a barrier to flexible practices, necessary to compete. An IMS relationship manager in C.5 commented on how the use of multiple IMS diminished a firm's ability to understand its holdings and therefore provide appropriate levels of transparency (A.6).

Seen as important for meeting regulatory obligations, the system monitored and aggregated individuals' compliance performance. Regulatory technology as a surveillance mechanism to enhance transparency created new rewards and sanctions, embedded within a structured framework of compliance rules and procedures. Individual trading decisions sanctioned and legitimized by applying and adhering to automated compliance rules had reputational advantages for client firms. Traders and Fund Managers voiced concerns about their loss of autonomy as the IMS enhanced their transparency, not only in how they executed and recorded trading decisions, but in their individual performance. In C.8, a senior manager responsible for several large client accounts resigned as the IMS exposed various incidents where compliance rules had been broken (A.5). Such cases were rare prior to the IMS introduction, as aggregated (team) performance did not expose individual interventions.

Against this backdrop, in 2007 the UK Regulator viewed the adoption of a growing number of prescriptive rules to have historically been unable to prevent misconduct and argued that increasing volumes of prescriptive rules were burdensome to the industry. During the period prior to the 2008 financial crisis, the UK Regulator advocated a principles-based approach to regulation as the most effective way to promote financial innovation, while also enabling firms to have some control over how they applied compliance rules. This surveillance approach allowed regulators to, '...move away from dictating through detailed, prescriptive rules and supervisory actions how firms should operate their business... In practice this means giving firms increased flexibility to decide more often for themselves what business processes and controls they should operate.' (FSA, 2007 p.7). This represented another major evolution of the regulatory landscape. Where the USA's SOX had focused on increasing controls and transparency to reduce 'incongruous risk taking', the UK Regulator now advocated the view that firms would have greater freedom in their business, specifically in the way they organized compliance processes and controls. The Regulator was seeking to foster financial innovation by allowing financial organizations greater autonomy in meeting regulatory requirements. While preferring a 
principles-based approach, regulatory technology increasingly constrained and reduced the autonomy of traders.

Over the period of the early 2000s to 2007, all eight firms were actively introducing technology to meet their compliance obligations conforming to a principles-based approach. Traders pointed to the 'technological surveillance' on individuals, with informants critical of the features and functionality of the software, especially 'bugs' and 'glitches' that could result in compliance breaches. IMS adoption was advocated as increasing operational efficiency, by preventing costly breaches before they occurred, and senior managers saw its strategic potential to win over new investors. The fund manager at C.6 commented 'when we are trying to win new customers, we discuss our IMS and compliance process. This re-assures the investor that we are using the very latest tools to comply with the new regulations'.

In summary, this period witnessed an unprecedented increase in financial technology with independent software vendors (ISVs) becoming partners rather than suppliers in the drive to enhance compliance and regulation of financial firms. Compliance was moving from a low level, administrative 'box-ticking exercise' to become an integral part of financial firms' activities. Surveillance, transparency and accountability further cascaded down the organizational and managerial hierarchy to enhance a compliance culture. Yet the rhetoric suggested a 'light-touch', principles-based approach, with less focus on penalties and sanctions for misconduct (A.5).

\section{The Post-crisis Period: 2008-2013}

In late 2007, the first signal of the impending global financial crisis sounded when BNP Paribas suspended redemptions to a fund heavily invested in US collateralized debt obligations (CDOs). Soon afterwards, Northern Rock (UK) failed. In 2008 Lehman Brothers, only the previous year ranked by Fortune magazine as the most admired US securities firm, went bankrupt. At Landsbanki (Iceland) British and Dutch depositors had to be rescued by their governments, as the bank announced it would only guarantee Icelandic deposits. In 2009, the G20 met in Pittsburgh and defined new measures aimed at preventing further financial crises. Through legislation, both the EU and US regulators worked towards meeting the G20 commitment to strengthen the global regulatory systems ${ }^{\mathrm{v}}$. From 2009-2010, the post-crisis regulatory landscape revealed a multitude of new obligations and rules (Sants, 2009; 2010). Table 5 captures the shifting priorities and practices of the post-crisis period. 


\begin{tabular}{|c|c|c|}
\hline Item & Theme & Interviewee Quote \\
\hline B.1 & $\begin{array}{l}\text { Empowerment of } \\
\text { the compliance } \\
\text { function }\end{array}$ & $\begin{array}{l}\text { 'I think [the compliance manager's] role [previous to the crisis] was as a check } \\
\text { and balance. They certainly did not have as much power as they have today. I } \\
\text { mean before theoretically they are able to say no; on occasion, they would be } \\
\text { overridden. Whereas now, when they say no, it's no!' } \\
\text { (Trader in C.8) } \\
\text { 'When I started working here, compliance was not seen as a major business } \\
\text { function. Since the crisis, we are constantly talking about better surveillance of } \\
\text { trading activities and possible sanctions for compliance breaches. Compliance is } \\
\text { now definitely on the agenda of top management' (Head of IT, C1). }\end{array}$ \\
\hline B. 2 & $\begin{array}{l}\text { IMS adoption } \\
\text { increases investors' } \\
\text { trust and confidence }\end{array}$ & $\begin{array}{l}\text { 'When we talk about trust, for the investors, they must feel that all of the processes } \\
\text { and procedures that are required to guarantee that their investments are being } \\
\text { managed within the regulations are in fact being managed by a process that } \\
\text { allows that.' (Trader in C.4) }\end{array}$ \\
\hline \multirow[b]{2}{*}{ B. 3} & $\begin{array}{l}\text { New regulations as } \\
\text { resource intensive } \\
\text { 'tick box' exercises }\end{array}$ & \multirow{2}{*}{$\begin{array}{l}\text { 'The problem is that [compliance] costs a lot of money and so in this very, very } \\
\text { competitive world, you do what you need to do so that you can tick the box for the } \\
\text { Regulator. The stuff you do, the added value stuff, almost is a second thought. If } \\
\text { there is money at the end of the year we will schedule a project for us to be able } \\
\text { to do that [optimize governance practices], unless the Regulator or someone says } \\
\text { to you, 'Why aren't you doing this? You need to be doing this as well.' } \\
\text { (Compliance manager, in C.7) }\end{array}$} \\
\hline & $\begin{array}{l}\text { Resource intensive } \\
\text { compliance } \\
\text { preventing } \\
\text { optimization of } \\
\text { governance }\end{array}$ & \\
\hline B. 4 & $\begin{array}{l}\text { Poor data quality } \\
\text { and presentation } \\
\text { reducing } \\
\text { transparency and } \\
\text { impacting } \\
\text { competence and } \\
\text { reputation }\end{array}$ & $\begin{array}{l}\text { '[C.4,] has nearly 10,000 compliance rules. Every single day, they have } 14,500 \\
\text { data exceptions, and they do not do anything apart from close them, because they } \\
\text { do not have the internal process and procedure to manage quality. If this became } \\
\text { public knowledge, the credibility of [C.4], would go absolutely further out the } \\
\text { window. It's really critical.' (IMS Relationship Manager for C.1-8) }\end{array}$ \\
\hline B. 5 & $\begin{array}{l}\text { IMS templates } \\
\text { guiding clients }\end{array}$ & $\begin{array}{l}\text { 'We develop templates for Dodd-Frank the rules. The requirement [for templates] } \\
\text { comes from the need for us to give advice and direction to the clients. The driver } \\
\text { is helping clients to define what the rules interpretation is and how they can best } \\
\text { apply it to their own environment.' (IMS Relationship Manager for C.1-8) }\end{array}$ \\
\hline
\end{tabular}

Table 5: Selected Post Crisis Period Themes and Data 2008- 2013

With the advantage of hindsight, principles-based regulation came in for criticism for creating a regime whereby the Regulator acted retrospectively to assess compliance breaches. The Regulator announced it was no longer content just to inspect material practices, systems and controls based on historical data. It now sought to evaluate the strategic arrangements and business models put in place by financial firms. This way, it would form a judgment on longterm risks across the entire business (Ashby and Waite, 2009; Turner, 2009). This more intrusive and direct mode of supervision was termed, the 'Intensive Supervisory Model' and formed a stepchange in financial regulation (Turner 2012a; 2012b). In the pre-crisis period, the regulator refrained from giving financial firms normative guidance on how they should develop a culture of compliance. This shifted in the post-crisis period, with more directive language and targets about the types of measures and metrics to effect cultural change. The revised approach focussed on developing frameworks for capturing, assessing and maintaining compliance regimes. A senior compliance manager in C.1 felt that much of the cost-benefit analysis conducted by the regulator, before introducing post-crisis approaches, had focused not on investor protection or on developing the public good but on the regulator managing its own reputational risk. His view was that increasing volumes of rules would require increasingly complex systems to implement these controls and that the costs of operationalising this new environment would eventually be passed onto the investors. Indeed, the incongruities between rules and principles based regulation lead the regulator to often focus on reactively assessing customer outcomes. Once a problem was identified, regulators reacted by requiring firms provide them all relevant data (this process was 
described as requiring 'maximum data'), and looking to identify evidence of breaches. This approach creates high costs as firms are required to identify and review large quantities of structured and unstructured data including employee email and chat room data to understand the conduct of employees. When an issue is found the regulator often acts reactively (sometimes years later) when the spoils of misdeeds may be long-gone. As result, the regulator introduced requirements for bonus payments to be delayed and recovered if malpractice was found. To be second-guessed by a regulator months or even years after an event, lead to increasing the already considerable costs of compliance.

Financial firms were under even greater pressure to implement systematic surveillance across all trading activity despite the regulatory landscape remaining a work-in-progress. Tight final deadlines for meeting compliance mandates required firms to implement technology and administrative systems even before the final draft of the regulations was agreed and set in place. Compliance became the 'third dimension' of governance and risk management. Regulators and consultancy practices promoted the trilogy of governance, risk and compliance (GRC) advocating that all industries (and not just those exclusively operating within financial services) develop a GRC strategy. Shifts in the regulatory landscape fuelled by the critical comments of politicians, industry commentators and media were in response to public anger about the conduct of financial firms. Demands for increased surveillance and transparency would empower the compliance function to exercise more control over financial traders (B.1).

Towards the late 2000s, best-of-breed IMSs were marketed as platform solutions spanning the entire enterprise. For most companies, the higher costs of supporting and maintaining multiple platforms was outweighed by a single system offering good levels of functionality across all product types. The compliance capabilities of the IMS used by firms in this study matured to cover any stage of the order lifecycle including clearing and settlement. Formulaic logic now allowed transactions to occur at the boundary of regulatory rules using real time prices, allowing for tighter control of the overall process. Increased data storage allowed both historical trend analysis and what-if scenario testing.

Ultimately, intensive supervision forced financial firms to inscribe more and more rules into the IMS for additional surveillance and reporting. Not all rules could be coded, or even fully understood. The complexity of obligatory risk calculations required measurements to be fed, often manually, into the IMS from dedicated risk management systems. Further attention was given to increasing transparency and monitoring performance by measuring how transactions were executed in markets ('best execution'), how trades were allocated to avoid privileging one investor over another ('timely allocation') and avoiding 'conflicts of interest' between financial intermediaries and investors.

The data suggested a shift in how the regulator viewed surveillance, transparency and accountability between the pre- and post-crisis periods, becoming more prescriptive in the types of administrative and technological systems and processes used in financial firms. C.6 had been fined, not because of a breach, but because they had continued to use Excel to create orders, despite having been told to upgrade to an IMS. Another firm argued that no IMS was available which could model business processes in the way they preferred. This argument held little sway with the regulator who objected to the hundreds of millions of pounds run through a simple desktop system. In the end, C.6 was forced to buy an IMS (they now run three), employing additional staff to manually copy across the orders generated in Excel. In contrast to the benefits of the system espoused in the pre-crisis period, this increased the costs of the trading process while also adding additional risks due to the potential for human error (i.e. entering the wrong data).

The study identified further changes in working practices. Compliance managers would engage with prospective investors during the sales process and even demonstrate the advantages of using their IMS. Investors could then see for themselves that orders are processed using robust 
technology (B.2). The compliance officer at C.3 added that 'whilst technology will generate the numbers, the role of compliance is to help drive the business process'. At C.1, the compliance function had become far more critical to the order lifecycle process. Three compliance officers located on the trading floor, armed with customised reports showing every rule run during the day, revealed how compliance was no longer a 'back-office-only' function. One officer commented, '10 years ago we were regarded as 'traffic wardens', but now we are no longer viewed as obstacles. We have become an essential part of the process, providing information such as who closed a breach, the date range or what had caused it."

Tight deadlines and voluminous rules imposed by a Regulator, keen to create a climate of fear and apply 'intense supervision' facilitated a 'box-ticking' approach to implementing regulations similar to that perceived by those implementing SOX (B.3). Much of the post-crisis regulations provided investors, stakeholders and society with a greater clarity over the risks associated with complex financial products. Often organizations struggled to source required data to support financial innovations and new regulatory obligations. Furthermore, data quality was an ongoing issue for some firms (B.4). The IMS Vendor had always seen data as one of the biggest obstacles to the efficient operation of trading activities, having built a system which now offered more than 1,000 data fields to support the vast array of different asset types that were being traded. As concerns about managing structured and unstructured data emerged, a new 'data service' was offered, however, all eight financial firms in our study decided not to implement this new service. With post-crisis budgets stretched, many clients were less keen to add to their already burgeoning compliance costs.

The IMS Vendor provided pre-written templates of automated rules for implementing specific areas of regulation for clients. Problems with these templates occurred because client firms differed in how they would collect, store and manipulate trading data. The IT Manager at C.1 said, 'The [Templates] that I have looked at, well let's say... we in the past have built very complex rules and the templates that I have seen have just used very simple code.' Another IT Manager, in C.7, highlighted data as a key issue, 'Because the structure of the underlying data differs from one house to another it impossible for a supplied template to be used out of the box.'

While standardization was an optimal and cost-effective goal for client firms, compliance managers faced a tension in retaining confidentiality about proprietary information and sharing common compliance issues with other firms, especially competitors. A compliance manager in company C.2 commented, 'Our number one focus is ensuring that we are meeting the requirements that are laid on us by the regulators. I guess it's evolved and it's now understood that one of the best and most effective ways of doing that is to find out what everyone else in the market is doing.' But a Compliance Manager at C.1 added, 'Although we share information with our competitors, we have to be careful about how much information we divulge. Managing data is a capability and we want to retain our core capabilities in how we serve clients'.

The IMS provided a configurable platform and a common language through which compliance managers share ideas for meeting compliance mandates without compromising intellectual property. We noted a trend from around 2010 to 2013 for compliance managers to share their views and concerns about the role of regulatory technology in financial regulation. The complexity and ambiguity of the post-crisis landscape was so great that compliance managers might share 'best practice', including, configurations for workflows, products and automated rules. In fact, the increasing appetite to impose punitive fines and sanctions on financial firms for non-compliance was becoming greater than retaining a previous compliance culture in which low surveillance, transparency and accountability seemed to thrive. 


\section{Discussion: Dialectic Tensions in Financial Regulation and Technology}

In this section, we reflect on the role of regulative technology in modern compliance functions, showing that software programs that embed pre-defined rules and functionality shape human inputs (i.e. compliance and trading decisions). Tensions, such as surveillance and ethical practices discussed in prior scholarly work, are relevant to our analysis of regulatory technology either side of the 2008 crisis. From our empirical analysis, we define a multi-level summary of regulatory compliance building on the concepts of surveillance, transparency and accountability (see Table 6). The analysis gives an overview of the dialectics of public regulatory bodies regarding how they impose conditions on privately controlled financial firms to meet transparency and accountability demands. In doing so, we underline the pluralistic nature of compliance and technology management. Our discussion delineates how events and multiple stakeholder interests, both internal and external to organizations, are colliding, conflicting and competing and thereby create dialectic tensions as rationalizations of transparency, surveillance and accountability shift (Van de Ven, and Poole). We build upon literature addressing how technology is implicated in synthesising, mediating and accentuating the dialectic tensions that we observed emerging during the course of our longitudinal study (Eaton et al 2017).

\begin{tabular}{|c|c|c|c|}
\hline $\begin{array}{l}\text { Macro-Micro } \\
\text { Levels of } \\
\text { Analysis } \\
\end{array}$ & Transparency & Surveillance & Accountability \\
\hline Societal & $\begin{array}{l}\text { 'Tsunami' of regulations } \\
\text { introduced to build } \\
\text { 'Culture of Compliance' } \\
\text { and reduce systemic } \\
\text { risks to economic } \\
\text { systems } \\
\end{array}$ & $\begin{array}{l}\text { Build institutional regulatory } \\
\text { co-operation and oversight } \\
\text { across national jurisdictions } \\
\text { (i.e. G20 commitments) }\end{array}$ & $\begin{array}{l}\text { Public calls to increase levels of } \\
\text { supervision and fines to tackle } \\
\text { malpractice where organizations } \\
\text { and individuals engage in self- } \\
\text { serving/unethical acts }\end{array}$ \\
\hline $\begin{array}{l}\text { Inter- } \\
\text { Organizational }\end{array}$ & $\begin{array}{l}\text { Reduce asymmetry of } \\
\text { knowledge and } \\
\text { information between } \\
\text { issuers, financial } \\
\text { intermediaries and } \\
\text { investors }\end{array}$ & $\begin{array}{l}\text { Regulators intensify } \\
\text { supervision of firms and } \\
\text { assesses their systemic } \\
\text { importance }\end{array}$ & $\begin{array}{l}\text { Impose rigid deadlines for reporting } \\
\text { regulatory outcomes by financial } \\
\text { organizations }\end{array}$ \\
\hline $\begin{array}{l}\text { Intra- } \\
\text { Organizational }\end{array}$ & $\begin{array}{l}\text { Increased pressure for } \\
\text { firms to better } \\
\text { understand operational, } \\
\text { credit and market } \\
\text { related risks across } \\
\text { organizational silos } \\
\end{array}$ & $\begin{array}{l}\text { Regulators focus on how } \\
\text { organizations achieve results } \\
\text { rather than just the outcomes }\end{array}$ & $\begin{array}{l}\text { Pressure to improve archiving and } \\
\text { auditing of financial data and } \\
\text { withholding of individuals' bonus } \\
\text { payments }\end{array}$ \\
\hline
\end{tabular}

Table 6: Multi-Level Regulation in the Financial Markets

As questions arise about prevailing governing regimes, revised structural arrangements containing different procedures and practices emerged. We theorize that past tensions emanating from competing rules and principles-based approaches create new tensions in the post-crisis period. Regulatory change increases the pressure on working practices and individuals to maintain heightened levels of transparency. No longer was simply reporting quantitative measures adequate but, increasingly regulators required firms to reflect and interpret outcomes qualitatively. C.2 commented 'Once my role was to produce the reports and that was it. Now I have to interpret them. Technology generates the numbers, but I now help drive understanding of the implications.' Surveillance tensions arise, in parallel, as new ideologies and related technological responses become situated between forces driven to retain the status quo. The IT Director at C.8 commented, 'The inability of or existing systems to provide the accurate data that we need [to run compliance checks] has forced us to buy another product'. Calls for increased 
accountability influence how companies engage with increasingly voluminous data sets to evidence outcomes. However, while regulators assume that audit trails can be strengthened through requiring the disclosure of 'maximum data' the reality is that underpinning data is not always easily obtainable or accessible. The compliance officer at C.1 said, 'Data is my biggest issue, I now have to spend an hour each morning just looking at why values are missing.' In summary, we theorize three distinct tensions arising from 'regulatory dialectics' (Kane, 1981): transparency and autonomy, surveillance and ethics, and accountability and data asymmetry. We argue that such tensions derive from paradoxical and contradictory regulatory ideologies, which shape inter- and intra-organizational approaches to meet compliance mandates.

\section{Transparency and Autonomy}

As regulatory technology became a material and symbolic requirement of regulators to enhance compliance activities among fund managers, traders and compliance managers, our empirical data points to an interesting dynamic between the requirement for increased transparency and reduced trader autonomy. In the pre-crisis, there were calls to eliminate moral hazards and increase transparency by reducing the data asymmetry between financial firms and other stakeholders (i.e. regulators and investors) (Solomon, 2013). Legislation requires rules codified in regulatory technology to become open to scrutiny. The IT manager at C.1 commented, 'Running checks in volatile markets is just getting harder. Valuations of complex products are worthless if we can't report on how it was done, let alone repeat the calculations run'. However, the focus on the financial firm also extended to individuals who act as part of a team. The trading audit at C.3 was used to justify why a trader was fired - individual activity could now be objectively measured. This ability to audit every single action was a powerful sales feature that provides a normative steer for existing and new industry entrants. Reducing trader autonomy was another important goal, particularly in the light of the many high profile 'rogue trader' stories in the media in recent years. Individuals implicated in financially motivated self-seeking behaviour (Roberts and Jones 2009) ensured regulatory technology occupied an important role (Mikes 2009).

Our empirical findings illustrate that transparency and trading autonomy are competing concepts. This is not to suggest they are mutually exclusive, or that a simple trade-off between them exists. Rather, these tensions emerge pluralistically, as actors and organizations react strategically and tactically to institutions. Differing rationalizations collide as individuals pursue their own interests by seeking to influence, create and maintain dominant institutional practices and rules (Roberts, 1991; Roberts and Jones, 2009). Building on this literature, our findings show that firms and individuals have considerable agency over how they respond to regulatory mandates. Through lobbying and consultation, actors and organizations may exert autonomy and influence, edit and moderate the regulatory regimes upon which they draw in order to build trust and enhance their transparency credentials (Roberts, 2001; Messner, 2009). They can control their regulatory footprint through selecting the financial products and markets in which they participate and the financial technology they adopt. In this way, firms can retain a level of autonomy and calibrate their exposure to regulatory regimes and the associated rules they must observe. Over the research period, there were five compliance meetings held at both the vendor's office or hosted at a client site. On several occasions, officials from the regulatory body would attend to discuss proposed regulation and also to solicit stakeholder (investor) feedback.

We observe how the regulator sought to increase transparency through tacitly coercing firms to adopt standardized technological systems where regulatory categories were coded in rules and thereby a holistic picture of holdings and exposure to risk was assumed (Mikes, 2011; Power, 2004). This is similar to other technologies, notably enterprise resource planning (ERP) systems, that have experienced significant data aggregation and quality challenges (Xu et al., 
2002). Our longitudinal data points to contradictions in the use of detailed evidence to monitor individual trading practices. If individual opportunity to exercise autonomy is highly constrained, both consciously and unconsciously, their level of accountability also diminishes (Butler, 2005; Gray, 2002). It may be unethical (or impractical) to require individuals to provide convincing accounts of themselves in difficult or challenging situations (Strathern, 2000). An example, postcrisis, is that the majority of actors implicated in the financial meltdown, who were compliant with the rules and regulatory structures in place, felt their actions were legitimate (Turner, 2012a; Gillespie et al., 2012).

As the UK regulator sought to impose common compliance practices by articulating which operational approaches are fit for purpose, we note that three firms in our sample received fines for not following the recommendations. Two of these incidents occurred at the pre-crisis stage, in a period issuing fewer sanctions and fines. Each example illustrates the confidence of the regulator in placing regulatory technology at the centre of meeting compliance mandates. Requirements had increased by such an extent that without automating compliance rules, it would be impossible to perform all the required checks. The regulator was creating rules where expected levels of transparency could only be achieved using a computer. An IT manager at C.8 commented 'We have decided on a long term change to all our accounting, risk, compliance and order management systems'. The benefit of running separate systems was preventing them from conducting calculations needed to evidence holistic transparency across the business and so meet the regulator's demands.

The extent to which regulatory technology increases transparency by reducing autonomy remains open to debate. The tension between transparency and trading autonomy plays out as standardised configurations of regulatory technology face burgeoning new rules with the potential for unforeseen outcomes. Embedded human and material agency simultaneously constrains and facilitates financial regulation (Leonardi, 2011). Traders and compliance teams work with existing regulatory technology to achieve profitable and compliant trades. But how this is achieved differs widely across client sites. Regulatory mandates interpreted and applied by financial firms are adapted to meet specific business objectives. Further tensions arise as compliance practices shaped by regulatory coercion (laws and rules) and normative pressures (industry and technology trends) built into the functionality of legacy systems, come into conflict with new rules and features.

\section{Surveillance and Ethical Practice}

Our pre-crisis data reveals an emerging tension between surveillance and ethics. As policy-makers advocated principles-based regulation to reduce the burden of prescriptive inflexible rule based regulations, (deemed unsuitable for keeping pace with dynamic markets and related product and service innovations), they sought to furnish financial firms with more opportunities to innovate and compete. This resulted in the blurring of the regulator's 'red line' and was rationalised as necessary to maintain London's attractiveness as a leading global financial hub. However, post-crisis, public outrage resulted in conflicting rationalizations advocating heightened surveillance of individuals' conduct, firm culture and customer outcomes directly conflicting with previously established notions regarding the merits of self-deterministic principals based regulation. New ideological approaches deemed to encourage good corporate relations and ethical practice were introduced. This paradigm shift was linked to new rhetoric regarding the consequences of imposing ill-defined principles based outcomes which in hindsight tended to obscure rather than simplify the regulator's position.

Embedded within the surveillance-ethical practice dialectic we observe is the notion that individuals can increasingly self-regulate to bring about cultural change (Black, 2008). True ethical conduct allows for individual reflection and the critical selection of ethical paths and 
correspondingly the self-imposed rejection of immoral actions (Bernauer and Mahon, 1994). Yet, through technical affordances, embedded in regulatory technologies, pathways are limited and workflows prescribed so such systems reduce opportunities for critical reflection (Latour 2005). This dialectic tension is also reflected in the colliding paradigms and conflicting goals of rules and principles based regulatory supervision. Where prescriptive rules seek to reduce and prohibit selectivity of action and so increase control, principles based regulation allows individuals space to adopt flexible and creative responses to meeting regulatory obligations. Following the financial crisis, the surveillance agenda became a top priority of regulators and government. UK, Europe and the US regulatory bodies developed a series of strategies to enhance financial regulation (FSA, 2007) and the emphasis shifted to try to synthesise the two contradictory approaches (Eaton et al 2017). The 'tsunami' of rules, some highly complex and requiring values generated by specialised risk systems, complicated the surveillance and ethical dialectic. While regulators, the media, some sections of the financial industry and investors called for more stringent structural rules and sanctions, the same groups also talked about individual agency and how trust and integrity needs to be improved. Heightened surveillance was now rationalised as an effective system of co-regulation where rules enable heightened levels of surveillance (Ford, 2010) and through political and industry pressure individuals are ecnouarged to become more reflective and ethical in their decision-making (Awrey et al., 2012; Gray, 2002; Power, 2007)).

Thus, the relationship between surveillance and ethics is not a simple trade-off, but instead, a co-constitutive dynamic with the potential for opposing ideologies and practices to influence one another. Our findings illustrate that rather than occupying a neutral position in the regulatory landscape, regulatory technology is viewed as a central feature of surveillance and ethical practices in financial firms. As a socio-technical system (Preda, 2006) the technology embeds the surveillance driven priorities and preferences of policy-makers and industry professionals. Widespread adoption of these systems across financial firms simultaneously shapes market strategies and regulatory mandates. The compliance manager at C.5 commented 'We are heavily influenced by [Asian Pacific] regulations which drives most of our system requirements', reflecting their need for a system based on implementing prescriptive rules and compliance checks as much as new product and service innovations.

The above examples illustrate the ideological and material features of surveillance and ethics with rules embedded in regulatory technology to meet prevailing compliance mandates. Conditions were much less rigorous in the pre-crisis period, becoming more burdensome to firms post-crisis. Paradoxically, as regulatory bodies imposed new surveillance rules and requirements on financial firms, instantiated in regulatory technology, increasingly automated trading environments suggested that individuals were less likely to question their own professional behaviour. Compliance mistakes were often attributed to 'technical glitches' or 'software bugs', rather than directly attributable to trader (human) error. Such rules embedded in centres of calculation thus allow the individual to look no further if the technology sanctions the trade, reassuring the individual they are operating within the rules (Leonardi 2011; Zammuto et al., 2007). Contributing to this conspiracy of calculation, the ISV, as the designer of the software applying rules and restricting working paractices, may further absolve the trader of any ethical responsibility for compliance breaches. A fund manager at C.6 commented 'I could not make sense of the compliance numbers for a new fund which was only worth fifty thousand pounds. I discovered that the check was using the wrong price'. This bug had been in the system for many years and the calculated difference was originally explained as a rounding error. The study indicates that regulatory technology, perceived in a positive light by regulators and financial executives, allows for greater formal surveillance of traders and fund managers, with trading decisions increasingly monitored and audited. This material feature measures the capacity of the technology to meet compliance mandates. Yet, over time informal cultural and behavioural factors, not easily codified in technical systems, fell under the surveillance radar. 


\section{Accountability and Data Asymmetry}

Driven by a need to introduce complex post-crisis regulations (Claessens and Kodres, 2014), we identify a tension between the need for enhanced accountability and continuing concerns about data asymmetry. The head of compliance at C.4 commented, "We have so many data sources that the compliance team involved with cleaning up the data is bigger than the trading desk!" Compliance managers at C1, C.5 and C.6 also commented on how they used a data warehouse to store a final version, or 'golden' copy, of audit dependent data. Each firm traded similar products but sourced their data from different providers creating disparate values hard to compare and contrast by the regulator. As the complexity of managing financial data increased, more cases of software bugs and 'rogue algorithms' blurred the boundary between individual accountability and computer failure. While regulatory technology mediates risks arising from market uncertainties - by implementing rules, metrics and measurements to increase transparency and accountability - unforeseen data flaws may result in wider, systemic problems. Over the twelve-year span of our data collection, the tension between accountability for introducing compliance rules and the growth in financial data was made more complicated by the increased use of technology vendors. Data quality and integrity became even more critical to financial firms. However, our research reveals responsibility for meeting regulatory mandates remains wholly with the regulated firm. This fuels tensions, as new rules to enhance oversight and accountability relate to who actually controls and manages the data.

While configuring regulatory technology data featured as an important challenge in the pre-crisis period, this challenge became acute in the post-crisis period. Asymmetric configurations of the system emerged. Rule interpretation and inscription differed between financial firms. The head of compliance at C.3 brought up the regulatory obligation to ensure 'fair allocation' saying, "This is simply not defined and is open to interpretation. Does it mean shares are allocated equally across all accounts in an order or in proportion to their order size or the funds value? What about if an order is filled across several days and what about an account changing its order size? The final decision is with the compliance team, even though the rule is the same." Homogeneity and heterogeneity co-exist at different levels within regulatory technologies as different terminology shapes coding, data sourcing and working practices across firms, despite using the same regulatory rules (Bamberger, 2010).

While the Regulator promotes technology as a means of reducing risk, findings show less attention given to design and data quality issues, with potentially serious consequences to the operational effectiveness of investment decisions. We observe that design issues surrounding the system require ongoing scrutiny, not only to monitor the activities of individuals, but also to observe how the system executes trading decisions. The man-machine interface became an even bigger issue following the financial crisis with more rules coded into the system. One company (C.2) discussed issues about quantity (number of orders) versus value-based orders (how much was spent). An order can be created for either the quantity that is bought (e.g. buy 5,000 IBM shares) or the value/cost (e.g. an investor wants to spend $£ 50,000$ on IBM shares). Initially, the system only supported the quantity-based methodology and the firm wanted to trade value-based unit trusts. Yet the cost of enhancing the system was over a $\$ 1 \mathrm{~m}$. The firm therefore decided to use workarounds using manual intervention. While this example is a simple illustration of how a financial firm builds functionality into regulatory technology, it has several implications for the relationship between accountability for trading activities and data management.

Conflicted and co-existing principles and rules based regulation increases the complexity of regulatory regimes. The financial firms in our study faced a dilemma. While they were required to demonstrate improvements in the stewardship of their organizations, by developing a robust and efficient compliance function, the race to keep pace with regulation meant increased 
outsourcing of data services to third parties. A lack of data quality directly affects the robustness of internal controls and risk mitigation (Fields et al., 1986). The cost of acquiring data was also increasing, but the integrity and soundness of data was not easily determined.

Contradictions arise as data availability and quality simultaneously empower and constrain individuals (Roberts, 2009: Tan, 2014). Our findings suggest, the regulator, while exerting pressure on financial firms to replace manual processes, had inadvertently created an 'automation bias' by overlooking the shortcomings of regulatory technology (Itami and Numagami 1992). Thus, trading decisions shaped by the design features embedded within the software reflect, not only the policy priorities of regulators and financial firms, but also the quality and availability of third party data. In making this point, we observe an under-theorized theme where the providers of market data are rarely scrutinised and do not come under serious regulatory purview. The availability and quality of underlying data provides a further layer of complexity (beyond the calculation of risk and market behaviours) to regulatory systems and so adds further opacity to trading activities (Bamberger, 2010). In this way, a contradiction emerges as regulators and vendors champion regulatory technology as a means to enhance transparency of trading activities, while data issues may serve to distort or obfuscate evaluation of risks and compliance breaches. An IT manager at C.6 commented that 'Data is fed into our own data warehouse. It is cleaned and scrubbed before being used by the IMS.' In other words, they decided on data values that were used. This is in stark contrast to the fund manager at C.3 who said that he had '... no confidence in the values that are saved'. Consequently, we identify a tension where data and, in particular, data provided by external third parties, simultaneously performs regulatory activities through the activities of third parties that fall under the radar of regulatory agencies.

\section{Conclusion}

Concepts of transparency, accountability and surveillance are mutually interdependent and co-constitutive of a compliance culture and the way individuals' behaviours are perceived. Regulatory technologies play a key role in markets as they systematize and disclose information to those in authority. Such technologies allow parties engaged in surveillance activities to review and evaluate transactions and related investment decisions to ensure they are appropriate and compliant and that corresponding internal controls remain effective. Regulatory technology designed to make trading decisions or practices transparent aim to reduce information asymmetry (Van den Brink et al., 2010). The technology provides a dual role in applying controls to enforce compliant behaviours, while also providing an audit trail to monitor performance using measurements and targets (Power, 2004). However, technology is not only a mechanism for applying controls and increasing data and information transparency, as it may also have potential to obfuscate or distort data and information (Kane, 1981).

The longitudinal study of the pre- and post-financial crisis shows that financial regulations and technologies continue to emerge in a complex global financial market. We theorize the introduction of regulatory technology in the context of dialectical tensions where financial regulators and companies oscillate between de-regulation and re-regulation of financial markets illustrated by principles-based and rules-based approaches (Black, 2008). Regulatory technology, as both a social and material artefact, is viewed as increasingly essential as a means to enhance surveillance and encourage ethical conduct and cultural change (Turner, 2012b). Our empirical data show that reacting to organizational and regulatory failures by introducing evermore controls enforces the adoption of regulatory technology to encode and apply high volumes of rules to individual transactions. Yet such automation comes at a price by re-defining and even limiting the scope of regulatory structures and analytical processes and increasing calculative complexity. 
The decision of policy makers and regulators to increase rules and controls using regulatory technology is mirrored by cultural assumptions that the correct way to react to corporate failures is to increase surveillance and transparency to reassure the public that formal measures are in place to heighten accountability (Messner, 2009). This study shows that regulatory technology, as a means of mitigating failures of governance through enhancing transparency, does not provide a simple solution for auditors to observe 'more sharply or more completely' (Roberts, 2009) the material and social components of regulatory compliance. As transparency cultures (Mikes, 2009) interpret and re-define compliance mandates (Callon, 2007), tensions ebb and flow across temporal and spatial boundaries.

The study invites further scholarship on how multi-jurisdictional regulatory mandates require the deployment of complex regulatory technologies to process increasingly large volumes of data during two very different periods in the financial timeline. Following the financial crisis, financial firms' accounting systems are becoming increasingly integrated with trading and compliance systems, with 'confrontations of codings' (algorithms) and 'codes of conduct' (market rules and regulations) (Lenglet, 2011) producing regulatory dialectics that obscure regulatory processes and outcomes rather than enhancing transparency and accountability. Many proposed rules now require risk metrics that without a computer would be impossible to calculate. This suggests the focus on technology infrastructure and applications becomes imperative in the regulatory mix in financial firms, requiring more cross-disciplinary research from computer science, finance, sociology, management and law. Combining work from these disciplines will extend the conceptual repertoire of scholarly research, particularly as financial firms, while looking to introduce the most effective and efficient technology, need also to consider the policy and legal implications of how selected technology will meet stringent compliance mandates. More specifically, research can address the consequences for firms who fail to meet new regulatory obligations, and the penalties and sanctions that follow. A further strand of research may study the post-crisis and global emergence of the new wave of financial technologies often termed 'fintechs' (mobile payments and remittances, robo-advisors, peer-to-peer lending, digital currencies etc.) and the means by which they are seeking to collaborate and compete with incumbent financial organizations.

Important questions are emerging regarding how regulators are responding to these new innovations. Indeed, the UK regulator's rationalization for regulatory sandboxes (which provide regulatory light environments where new fintechs can grow without the burden of being subject to the full regulatory regime) as necessary to foster innovation and competition are reminiscent of the justifications offered for principles based regulation. Indeed, the 2016 G20 'High Level Principles for Digital Financial Inclusion' refer to a need for legal and regulatory frameworks to allow pilots of fintech innovations. There is a growing global acceptance among regulators that the burden of regulation has become too onerous and that new 'regtech' start-ups, often funded by venture capitalists, have the potential to reduce regulatory complexity and correspondingly barriers to engaging in regulated activities faced by new entrants. This paper provides insight into the regulatory, management and technological antecedents of the global fintech/regtech phenomenon.

In summary, financial regulation is revealed not only by, or managed through, conventional control and measurement systems, but made more challenging as financial innovation (e.g. trading algorithms) create the conditions for new regulatory panics across financial markets. The introduction of new technologies (blockchain, machine learning and artificial intelligence) are further removing human beings from transactions and so create new challenges for regulators to ensure appropriate systems of transparency, surveillance and accountability. 


\section{References}

Aloui, R., Aïssa, M.S.B., and Nguyen, D.K. (2011). Global Financial Crisis, Extreme Interdependences, and Contagion Effects: The Role of Economic Structure?, Journal of Banking \& Finance, 35:1, $130-141$.

Alvesson, M. and Deetz, S. (2000). Doing Critical Management Research. London: Sage Publications Ltd.

Arnold, P. (2005). Disciplining domestic regulation: the World Trade Organization and the market for professional services, Accounting, Organizations and Society, 30:4, 299-330.

Arnold, P. (2009). Global financial crisis: The challenge to accounting research, Accounting, Organizations and Society, 34:6, 803-809.

Ashby, S., and Waite, N. (2009). The Turner Review on the Global Banking Crisis: A Response from the Financial Services Research Forum. Retrieved 8th June, 2012, from http://www.nottingham.ac.uk/business/forum/documents/researchreports/paper61.pdf

Avgerou, C. (2013). "Social Mechanisms for Causal Explanation in Social Theory Based Is Research," Journal of the Association for Information Systems, (14:8), pp. 399-419.

Awrey, D., Blair, W., and Kershaw, D. (2012). Between Law and Markets: Is There a Role for Culture and Ethics in Financial Regulation?, LSE Legal Studies Working Paper No. 14/2012.

Bamberger, K.A. (2010). Technologies of Compliance: Risk and Regulation in a Digital Age, Texas Law Review 8:4, 669-739.

Barratt, E. (2008). The Later Foucault in Organization and Management Studies, Human Relations, 61:4, 515-537.

Barth, M.E., and Landsman, W.R. (2010). How Did Financial Reporting Contribute to the Financial Crisis?, European Accounting Review 19, 399-423.

Becker, H.S, (1958). "Problems of Inference and Proof n Partcipant Observation" American Sociological Review, (23:6), pp. 652-660.

Benston, G.J. (2006). Fair-Value Accounting: A Cautionary Tale from Enron, Journal of Accounting and Public Policy 25:4, 465-484.

Bernauer, J.W., and Mahon, M. (1994). 6 the Ethics of Michel Foucault, In G. Gutting (Eds.). The Cambridge Companion to Foucault, (pp. 141-151). Cambridge: Cambride University Press.

Black, J. (2001). Decentering Regulation, Current Legal Problems 54, 103-146.

Black, J. (2008). Forms and Paradoxes of Principles-Based Regulation, Capital Markets Law Journal 3:4, 425-457.

Black, J., Hoper, M., and Band, C. (2007). Making a Success of Principles-Based Regulation, Law \& Fiancial. Markets Review 1:3, 191-206.

Blyth, M. (2003). The Political Power of Financial Ideas: Transparency, Risk and Distribution in Global Finance, in J. Kirshner (Eds.) Monetary Orders, Ambiguous Economics, Ubiquitous Politics, (pp. 239-59). Ithaca: Cornell University Press.

Bossewitch, J., and Sinnreich, A. 2013. "The End of Forgetting: Strategic Agency Beyond the Panopticon," New Media \& Society (15:2), pp. 224-242.

Burawoy, M. (2003). Revisits: An Outline of a Thoery of Reflexive Ethnography. American Sociological Review, 68, 645-679.

Butler, J. (2005). Giving an account of oneself. New York: Fordham University Press.

Callon, M. (2007). What does it mean to say that Economics is Performative? In D. Mackenzie, F. Muniesa and L. Siu (Eds.) Do Economists Make Markets? On the Performativity of Economics, Princeton: Princeton University Press.

Callon, M., and Muniesa, F. (2005). Economic Markets as Calculative Collective Devices, Organization Studies, 26:8, 1229-1250.

Claessens, S and Kodres, L. (2014). The Regulatory Responses to the Global Financial Crisis: Some Uncomfortable Questions. IMF Working Paper, WP/14/46.

Cleven, A., and Winter, R. (2009). Regulatory Compliance in Information Systems Research - Literature Analysis and Research Agenda, Enterprise, Business-Process and Information Systems Modeling, 29:1, 174-176. 
Cliff, D. and L. Northrop (2010), "The Global Financial Markets: An Ultra-Large Scale Systems Perspective", Foresight: The Future of Computer Trading in Financial Markets driver review DR4, Report for the Government Office for Science.

Collinson, D.L. (1999). Surviving the Rigs': Safety and Surveillance on North Sea Oil Installations, Organization Studies 20:4, 579-600.

Currie, W.L. (2008). Institutionalization of IT compliance: A longitudinal study, International Conference on Information Systems, Paris, France, December.

De Haas, R., and Van Horen, N. (2012). 'International Shock Transmission after the Lehman Brothers Collapse: Evidence from Syndicated Lending,' American Economic Review Papers \& Proceedings, 102:3, 231-237.

DeWalt, K., and DeWalt, B.R. (2012). Participant Observation: A Guide for Fieldworkers, Plymouth UK: AltaMira Press.

Drury, S. and Scott, C., (2001). "Bias as a Research Strategy in Participant Observation: The Case of Intergroup Conflict" Field Methods, (13:1), pp. 47-67.

Eaton, B., Hedman., J and Medaglia, R.J. "Three different ways to skin a cat: financialization in the emergence of national e-ID solutions" Journal of Information Technology doi:10.1057/s41265017-0036-8

Eisenhardt, K.M. (1989). "Building Theories from Case Study Research," The Academy of Management Review (14:4), pp. 532-550.

Eisenhardt, K.M., and Graebner, M.E. (2007). "Theory Building from Cases: Opportunities and Challenges," Academy of management journal (50:1), pp. 25-32.

Fayard, A.-L., and Weeks, J. 2007. "Photocopiers and Water-Coolers: The Affordances of Informal Interaction," Organization studies (28:5), pp. 605-634.

FCA. (2014). FCA Risk Outlook 2014. Retrieved 4th May, 2014, from http://www.fca.org.uk/static/documents/corporate/risk-outlook-2014.pdf

Fields, K., Sami, H., and Sumners, G. (1986). Quantification of the Auditor's Evaluation of Internal Control in Data Base Systems, The Journal of Information Systems 1:1, 24-77.

Flick, U. (1998). An Introduction to Qualitative Research. London, UK: Sage.

Fligstein, N., and Habinek, J. (2014). Sucker Punched by the Invisible Hand: The World Financial Markets and the Globalization of the US Mortgage Crisis, doi:10.1093/ser/mwu004, pp.1-29.

Ford, C.L. (2010). Principles-Based Securities Regulation in the Wake of the Global Financial Crisis, McGill Law Journal, 55:2, 257-307

Franks, J., Mayer, C., and Rossi, S. (2009). Ownership: Evolution and Regulation, in Review of Financial Studies. 4009-4056.

FSA. (2007). Principles-Based Regulation Focusing on the Outcomes That Matter. Retrived April $5^{\text {th }}$ 2009, from.

Funk, R.J. and D. Hirschman, D. 2014. Derivatives and Deregulation: Financial Innovation and the Demise of Glass-Steagall. Administrative Science Quarterly, 59 (4) 669-704.

Geertz, C. (1973). The Interpretation of Cultures: Selected Essays. New York: Basic Books.

Gillespie, N., Hurley, R., Dietz, G., and Bachmann, R. (2012). Restoring Institutional Trust after the Global Financial Crisis, In R. Kramer and L. Pittinsky (Eds.) Resotoring Trust in Organizations and Leaders: Enduring Challanges and Emerging Answers, New York: Oxford University Press.

Glaser, F. and Risius, M. (2017) "Effects of transparency: analyzing social biases on trader performance in social trading" Journal of Information Technology doi:10.1057/s41265-016-0028-0

Golden, B.R. (1992). "Research Notes. The Past Is the Past—or Is It? The Use of Retrospective Accounts as Indicators of Past Strategy," Academy of Management Journal (35:4), pp. 848-860.

Gozman, D., and Currie, W. (2014). The Role of Investment Management Systems in Regulatory Compliance: A Post-Financial Crisis Study of Displacement Mechanisms, Journal of Information Technology 29,. 44-58.

Gray, R. (2002). The social accounting project and accounting organizations and society. Privileging engagement, imaginings, new accountings and pragmatism over ritique? Accounting, Organizations and Society, 27:7,.687-708

Greenspan, A. (2008). Transcript of testimony to House Oversight Committee Retrived April $12^{\text {th }} 2012$, from http://oversight.house.gov/documents/20081024163819.pdf 
Greenwald, B.C., and Stiglitz, J.E. (1990). Asymmetric Information and the New Theory of the Firm: Financial Constraints and Risk Behaviour, The American Economic Review 80:2, 160-165.

Guest, G., MacQueen K, M., and Namey E, N. (2012). Applied Thematic Anlaysis. Thousand Oaks: Sage.

Hansen, H.K., and Flyverbom, M. 2015. "The Politics of Transparency and the Calibration of Knowledge in the Digital Age," Organization (22:6), pp. 872-889.

Humphrey, C., Loft, A., Woods, M (2009) The global audit profession and the international financial architecture: Understanding regulatory relationships at a time of financial crisis. Accounting, Organizations and Society, 34, 810-825.

Iedema, R., and Rhodes, C. (2010). The Undecided Space of Ethics in Organizational Surveillance, Organization Studies 31:2, 199-217.

Itami, H., and Numagami, T. (1992). Dynamic Interaction between Strategy and Technology, Strategic Management Journal 13:S2, 119-135.

Kane, E. (1981). Accelerating inflation, Technological Innovation, and the Decreasing Effectiveness of Bank Regulation. Journal of Finance, 36:2, 355-367.

Kauffman, R.J., Liu, J., Ma D., (2014), "Innovations in Financial IS and Technology Ecosystems: Highfrequency Trading in the Equity Market", Technological Forecasting and Social Change, 39-354.

Krawiec, K. D. (2000). Accounting for Greed: Unraveling the "Rogue Trader" Mystery, Oregon Law Review 79, 301-338.

Kvale, S., and Brinkmann, S. (2009). Interviews Learning the Craft of Qualitative Research Interviewing. Thousand Oaks, CA: Sage.

Lee, A., and Baskerville, R. (2003). "Generalizing Generalizability in Information Systems Research," Information Systems Research (14:3), pp. 221-243.

Lenglet, M. (2011). Conflicting Codes and Codings: How Algorithmic Trading is Reshaping Financial Regulation. Culture \& Society, 28:6, 44-66.

Leonard-Barton, D. (1990). "A Dual Methodology for Case Studies: Synergistic Use of a Longitudinal Single Site with Replicated Multiple Sites," Organization science (1:3), pp. 248-266.

Leonardi, P.M. (2011). When Flexible Routines Meet Flexible Technologies: Affordance, Constraint, and the Imbrication of Human and Material Agencies, MIS Quarterly 35:1, 147-167.

Li, T. van Dalen P. and van Rees (2017) "More than just noise? Examining the information content of stock microblogs on financial markets" Journal of Information Technology oi:10.1057/s41265-

Messner, M. (2009). The Limits of Accountability, Accounting, Organizations and Society, (34), pp. 918938.

Mikes, A. (2009). Risk Management and Calculative Cultures. Management Accounting Research, 20, pp. 18-40.

Mikes, A. (2011). From Counting Risk to Making Risk Count: Boundary-Work in Risk Management, Accounting, Organizations and Society, 36, pp. 226-245.

Miles, M.B., and Huberman, M. (1994). Qualitative Data Analysis: An Expanded Sourcebook, (2nd ed.). Thousand Oaks CA: Sage.

Miller, P., and Napier, C. (1993) Genealogies of Calculation, Accounting, Organizations and Society, (18), pp. 631-647.

Miller, P., Kurunmaki, L., O'Leary, T. (2008) Accounting, Hybrids and the Management of Risk, Accounting, Organizations and Society, 33, 942-967.

Muniesa, F., Millo, Y., and Callon, M. (2007). An Introduction to Market Devices, The Sociological Review (55:s2), 1-12.

Orlikowski, W.J., and Iacono, C.S. (2001). "Research Commentary: Desperately Seeking the" It" in It Research-a Call to Theorizing the IT Artifact," Information Systems Research (12:2), pp. 121134.

Patton, M. (1990). Qualitative Evaluation and Research Methods. Beverley Hills, CA: Sage.

Perrow, C. (1985). Review Essay: Overboard with Myth and Symbols, American Journal of Sociology 91, 151-155.

Pettigrew, A.M. (1985). "Contextualist Research: A Natural Way to Link Theory and Practice," in Doing research that is useful in theory and practice, E.E Lawler A.M Mohrman S.A. Mohrman G. Ledford and T,G Cummings (eds.) Oxford, UK: Lexington Books, pp. 222-273. 
Pettigrew, A.M. (1990). "Longitudinal Field Research on Change: Theory and Practice," Organization Science (1:3), pp. 267-292.

Power, M. (2000). The Audit Society - Second Thoughts. International Journal of Auditing, 4, 111-119.

Power, M. (2004), Counting, control and calculation: Reflections on measuring and management. Humans Relations, 57:6, 765-783.

Power, M. (2007)Organized Uncertainty Designing a World of Risk Management Oxford, UK: Oxford University Press.

Preda, A. (2006). Socio-Technical Agency in Financial Markets the Case of the Stock Ticker, Social Studies of Science 36:5, 753-782.

Punch, K.F. (2005). Introduction to Social Research: Qualitative and Quantitative Approaches, (2nd ed.). London: Sage.

Radcliffe, V.S., Cooper, D.J., Robson, K. (1993). The Management of Professional Enterprises and Regulatory Change: British Accountancy and the Financial Services Act, 1986 http://papers.ssrn.com/so13/papers.cfm?abstract_id=2269384

Roberts, J and Jones, M. (2009). Accounting for self interest in the credit crisis, Accounting, Organizations and Society, 34: 6-7, 856-867

Roberts, J. (1991). The possibilities of accountability, Accounting, Organizations and Society, 16:4, 35568.

Roberts, J. (2001). Trust and control in Anglo-American systems of corporate governance: The individualizing and socializing effects ofprocesses of accountability', Human Relations,54:12, $1547-1572$.

Roberts, J. (2009). No one is perfect: The limits of transparency and an ethic for 'intelligent' accountability Accounting, Organizations and Society, 34: 8, 957-970.

Saldana, J. (2009). The Coding Manual for Qualitative Researchers. Thousand Oaks: Sage.

Sanjek, R. (1990) "A Vocabulary for Fieldnotes" in Fieldnotes: The Makings of Anthropology, R.Sanjek (ed.), pp187-270, Ithaca: Cornell University Press.

Sants, H. (2009). 'Delivering Intensive Supervision and Credible Deterrence.' Retrieved 23rd March, 2009 , from http://www.fsa.gov.uk/pages/Library/Communication/Speeches/2009/0312_hs.shtml

Sants, H. (2010). UK Financial Regulation: After the Crisis. Retrieved 17th March, 2010, from http://www.fsa.gov.uk/pages/Library/Communication/Speeches/2010/0312_hs.shtml

Schinckus, C. (2017) "An essay on financial information in the era of computerization" Journal of Information Technology doi:10.1057/s41265-016-0027-1

Schwartz, S.M and Schwartz, C. G. (1955). "Problems in Participant Observation" American Journal of Sociology (60:4), pp. 343-353

Seale, C. (1999). "Quality in Qualitative Research," Qualitative Inquiry 1999 (5), pp. 465-478.

Sewell, G., and Barker, J.R. (2001). Neither Good, nor Bad, but Dangerous: Surveillance as an Ethical Paradox, Ethics and Information Technology 3:3, 181-194.

Shearer, T. (2002). Ethics and accountability: From the for-itself to the fort-the-other. Accounting, Organizations and Society, 27, 541-573.

Siereing, M, Clapham B Engel, O and Gomber, P (2017) “A taxonomy of financial market manipulations: establishing trust and market integrity in the financialized economy through automated fraud detection" Journal of Information Technology doi:10.1057/s41265-016-0029-z

Siggelkow, N. (2007). "Persuasion with Case Studies," Academy of Management Journal (50:1), pp. 2024.

Silverman, D. (2001). Interpreting Qualitative Data: Methods for Analyzing Talk, Text and Interaction, (2nd ed.). London, UK: Sage.

Somerville I., Cliff . D., Calinescu R., Keen J., Kelly T., Kwiatkowska L., Mcdermid J. and R. Paige (2012), "Large-Scale Complex IT Systems", Communications of the ACM, 55(7), 71-77.

Soin, K., and Huber, C. (2013). Financial Scandal!! Regulation? Carr Research: Risk and Regulation, Winter 2013.16-17.

Solomon, J. (2013). Corporate Governance and Accountability, (4th ed.). Chicester: Wiley.

Spicer, A., and Sewell, G. (2010). From National Service to Global Player: Transforming the Organizational Logic of a Public Broadcaster. Journal of Management Studies, 47(6). 
Strathern, M. (2000). 'The tyranny of transparency.' British Educational Research Journal, 26:3,. 309321.

Symon, G., and Cassell, C. (2012). Qualitative Organizational Research: Core Methods and Current Challenges. London, UK: Sage.

Tan, Z. (2014). The construction of calculative expertise: The integration of corporate governance into investment analyses by sell-side financial analysts. Accounting, Organizations and Society, 39, 362-364.

Tiejun, M and McGroaty, F. (20127) "Social Machines: how recent technological advances have aided financialisation" Journal of Information Technology doi:10.1057/s41265-017-0037-7

Tsatsou, P., Elaluf-Calderwood, S, and Liebenau, J. (2009). "Towards a Taxonomy for Regulatory Issues in a Digital Business Ecosystem in the Eu," Journal of Information Technology (25:3), pp. 288307.

Turner, A. (2009). The Turner Review a Regulatory Response to the Global Banking Crisis, Retrieved 17th March, 2010, from http://www.fsa.gov.uk/pubs/other/turner_review.pdf

Turner, A. (2012a). Banking at the Cross-Roads: Where Do We Go from Here? Retrieved 2012, 22nd December, from http://www.fsa.gov.uk/library/communication/speeches/2012/0724-at.shtml

Turner, A. (2012b). 'Mansion House Speech.' Retrieved 20th October, 2012, from http://www.fsa.gov.uk/library/communication/speeches/2012/1011-at.shtml

Van de Ven, A. H. and M. S. Poole (1995). "Explaining development and change in organizations." Academy of management review 20(3): 510-540.

Williams, J.W. (2012). Policing the Markets. Routledge, Oxon, UK.

Williams, J.W. (2013). Regulatory Technologies, Risky Subjects, and Financial Boundaries: Governing 'Fraud' in the Financial Markets,' Accounting, Organizations and Society 38:6, 544-558.

$\mathrm{Xu}, \mathrm{H}$., Nord, J.H., Brown, N., and Nord, G.D. (2002). Data Quality Issues in Implementing an ERP, Industrial Management \& Data Systems, 102:1, 47-58.

Yin, R. (2009). Case Study Research: Design and Methods, (4th ed.). Los Angeles: Sage.

Zaloom, C. (2003). 'Ambiguous Numbers: Trading Technologies and Interpretation in Financial Markets,' American Ethnologist (30:2), pp. 258-272.

Zammuto, R.F., Griffith, T.L., Majchrzak, A., Dougherty, D.J., and Faraj, S. (2007). "Information Technology and the Changing Fabric of Organization," Organization Science (18:5), pp. 749762.

Zhang, X.M., and L. Zhang (2015), "How Does the Internet Affect the Financial Market? An EquilibriumModel of Internet-Facilitated Feedback Training", Management Information Systems Quarterly, 39.

\footnotetext{
${ }^{\text {i }}$ Regulatory technology is a relatively new term encompassing not only surveillance technologies but also applications focused on facilitating compliant outcomes through monitoring and reporting. Investment Management Systems (IMSs) are included under Regulatory Technology and the term is relevant for defining IT for use in the financial services industry.

ii For Example, in 2016 the UK Regulator ran a two-day 'hackathon' event to develop solutions for 'Unlocking Regulatory Reporting'.

iii The USA presented sweeping changes by way of the USA Patriot Act (2001) and the Sarbanes-Oxley Act of 2002 (SOX). The European Union issued several new directives such as the Market Abuse Directive (MAD I, 2005) or the Markets in Financial Instruments Directive (MiFID I, 2007) and after many years agreed on updates to its Undertaking for Collective Investments in Transferable Securities (UCITS III, 2001). In addition, the Basel Committee on Banking Supervision which represents 27 countries, (including nine EU countries and the USA), updated its banking supervision policy (Basel II, 2001).

iv The EU updated UCITS (2009) and the Capital Requirements Directive (CRD, 2009 and 2010) and brought out the Alternative Investment Fund Managers Directive (AIFMD) in 2011. The USA saw its most sweeping reform changes since the Bank Acts of the 1930s when the DoddFrank Wall Street Reform and Consumer Protection was signed into law in 2010. This was an attempt to restore public confidence following the crisis, adding almost 400 rules, with the highest proposed in the areas of derivatives, consumer protection and mortgage reforms. The Third Basel Accord of 2010-2011 was implemented in 2013.

${ }^{v}$ The European Union's regulatory response to the crisis fragmented into several updated European Directives (e.g. UICITS IV) as well as new directives (AIFMD) and regulations (EMIR) which contained sets of prescriptive rules. In contrast, the US opted to develop a single sweeping piece of legislation known as the Dodd-Frank Wall Street Reform and Consumer Protection Act, passed in 2010. This 850-page document amends many earlier acts, adding almost 400 rules.
} 
